\title{
Improving Soil Moisture and Surface Turbulent Heat Flux Estimates by Assimilation of SMAP Brightness Temperatures or Soil Moisture Retrievals and GOES Land Surface Temperature Retrievals ${ }^{\mathscr{O}}$
}

\author{
YANG Lu AND SusAn C. STEELE-DunNe \\ Department of Water Management, Faculty of Civil Engineering and Geosciences, Delft University of Technology, \\ Delft, Netherlands
}

GABRIËLlE J. M. DE LANNOY

Department of Earth and Environmental Sciences, Katholieke Universiteit Leuven, Heverlee, Belgium

(Manuscript received 9 June 2019, in final form 8 October 2019)

\begin{abstract}
Surface heat fluxes are vital to hydrological and environmental studies, but mapping them accurately over a large area remains a problem. In this study, brightness temperature (TB) observations or soil moisture retrievals from the NASA Soil Moisture Active Passive (SMAP) mission and land surface temperature (LST) product from the Geostationary Operational Environmental Satellite (GOES) are assimilated together into a coupled water and heat transfer model to improve surface heat flux estimates. A particle filter is used to assimilate SMAP data, while a particle smoothing method is adopted to assimilate GOES LST time series, correcting for both systematic biases via parameter updating and for short-term error via state updating. One experiment assimilates SMAP TB at horizontal polarization and GOES LST, a second experiment assimilates SMAP TB at vertical polarization and GOES LST, and a third experiment assimilates SMAP soil moisture retrievals along with GOES LST. The aim is to examine if the assimilation of physically consistent TB and LST observations could yield improved surface heat flux estimates. It is demonstrated that all three assimilation experiments improved flux estimates compared to a no-assimilation case. Assimilating TB data tends to produce smaller bias in soil moisture estimates compared to assimilating soil moisture retrievals, but the estimates are influenced by the respective bias correction approaches. Despite the differences in soil moisture estimates, the flux estimates from different assimilation experiments are in general very similar.
\end{abstract}

\section{Introduction}

Surface heat fluxes, and in particular their spatial pattern and temporal evolution, are crucial for surface energy balance (SEB) as well as terrestrial water cycle studies (McCabe and Wood 2006; Bateni and Entekhabi 2012). However, in situ measurements are difficult and expensive, and are limited to only a few in situ flux networks (Baldocchi et al. 2001; Ma and Szilagyi 2019; Xu et al. 2019). In addition, the heterogeneous nature of heat fluxes further complicates their interpolation and extrapolation in the spatial domain (Semmens et al. 2016).

\footnotetext{
Supplemental information related to this paper is available at the Journals Online website: https://doi.org/10.1175/JHM-D-190130.s1.
}

Corresponding author: Yang Lu, y.lu-1@tudelft.nl
Remote sensing techniques have great potential for monitoring land surface variables continuously over a large area. Although surface heat fluxes cannot be observed directly from space, many studies have used remote sensing products for surface heat flux estimation. For example, "triangle methods" estimate fluxes by assuming a statistical relationship between the fluxes and observable environmental indicators such as vegetation indices and land surface temperature (LST) (Minacapilli et al. 2016; Chirouze et al. 2014; Zhu et al. 2017). Other studies have mainly focused on using remote sensing data as input for SEB models (Su 2002; Bastiaanssen et al. 1998a,b; Allen et al. 2007; Kustas et al. 1996; Holmes et al. 2018; Jiang and Islam 2001; Anderson et al. 2011) or land surface models (LSMs) (Oleson et al. 2010; Zheng et al. 2015). These models apply to a wide range of conditions but require a relatively large suite of input data (Lu et al. 2017). 
Aside from the direct modeling approaches, some studies have assimilated in situ or remotely sensed LST data for flux estimation (Bateni and Entekhabi 2012; Bateni and Liang 2012; Bateni et al. 2013; Caparrini et al. 2003, 2004b,a; Xu et al. 2014, 2018) into simple SEB models. The rationale is that LST time series contain information on energy partitioning over the land surface. These studies estimate fluxes by determining two key parameters: a neutral bulk heat transfer coefficient $C_{H N}$ and an evaporative fraction (EF). The $C_{H N}$ determines the sum of sensible and latent heat fluxes, while EF represents the partitioning between them. In these studies, $C_{H N}$ is often assumed constant during a month, and EF is assumed constant in the daytime window (0900-1600 LT) on sunny days. Thanks to the assumptions, these methods only require a limited amount of input data. Some studies have demonstrated that the flux estimates can be further improved by constraining EF using soil wetness information calculated from precipitation data (Sini et al. 2008), or in situ soil moisture measurements (Farhadi et al. 2014; Lu et al. 2016) or remote sensing (Farhadi et al. 2016; Lu et al. 2017; Xu et al. 2019) soil moisture retrievals.

A potential risk of assimilating remotely sensed soil moisture retrievals lies in the retrieval algorithm, which utilizes land surface parameters and background information including, for example, LST data. These data are often outputs of other models, which may be inconsistent with, or even contradictory to the model simulations in the assimilation system. Furthermore, the retrieval errors will be correlated to ancillary data, which in turn may be correlated to the background information used in data assimilation (De Lannoy and Reichle 2016b). Therefore, it is natural to consider assimilation of brightness temperature (TB), which is the direct measurement of satellite microwave radiometers. It is more difficult to assimilate TB observations than soil moisture retrievals since TB is indirectly related to land surface variables. A radiative transfer model (RTM) needs to be adopted as the observation operator to translate modeled land surface variables into TB simulations. Several TB assimilation studies have been conducted, which have used TB observations from Advanced Microwave Scanning Radiometer for Earth Observing System (AMSR-E) (Tian et al. 2009; Zhao et al. 2016; Yang et al. 2016) and Soil Moisture Ocean Salinity (SMOS) (De Lannoy and Reichle 2016a,b; Lievens et al. 2016, 2017a), and mainly focused on improving soil moisture estimates.

Launched in January 2015, the Soil Moisture Active Passive (SMAP) mission is the latest mission dedicated to soil moisture monitoring. The microwave radiometer onboard SMAP provides global soil moisture measurement at 36-km scale and 2-3-day revisit time. Validation studies suggest that SMAP can characterize the soil moisture temporal evolution accurately (Pan et al. 2016; Colliander et al. 2017; Cai et al. 2017). Recently, Lu et al. (2017) demonstrated that surface heat flux estimates can be improved by the assimilation of SMAP soil moisture retrievals and Geostationary Operational Environmental Satellite (GOES-East) LST data into a coupled water and heat transfer model, and that incorporating soil moisture data significantly improves flux estimation thanks to the positive correlation between EF and soil moisture (Gentine et al. 2007; Santanello et al. 2011; Farhadi et al. 2014). However, SMAP TB assimilation studies are limited to, for example, the operational SMAP Level-4 data products (Reichle et al. 2017a,b) and a few studies on soil moisture estimation (Lievens et al. 2017b) or numerical weather forecasting (Carrera et al. 2019). No studies so far have focused on surface heat flux estimation or the differences between assimilating $\mathrm{TB}$ observations and soil moisture retrievals.

The goal of this study is to determine if the assimilation of physically consistent TB and LST data could yield improved soil moisture and surface turbulent heat flux estimates. Here SMAP TB observations at either horizontal or vertical polarization are assimilated together with GOES LST data, and the experiments are compared to a third experiment which assimilates GOES LST data and SMAP soil moisture retrievals following Lu et al. (2017). The objective is to investigate the information contained in SMAP TB observations for surface turbulent heat flux estimation in comparison with that from SMAP soil moisture retrievals, through assimilation with GOES LST data, and to provide insight into the differences in using horizontally or vertically polarized TB data.

This paper is structured as follows: section 2 introduces the datasets and model framework, including the state propagation model and radiative transfer model as well as the bias correction approach. The model simulation assessment and the estimates for soil moisture and fluxes are given in section 3. Finally the conclusions are summarized in section 4 .

\section{Materials and methods}

\section{a. Study area and data}

The methodology is applied over an area $\left(35.75^{\circ}-\right.$ $\left.37.24^{\circ} \mathrm{N}, 96.72^{\circ}-98.21^{\circ} \mathrm{W}\right)$ in the U.S. Southern Great Plains (SGP). The study area is covered by $4 \times 4$ SMAP TB cells posted on a 36-km Equal-Area Scalable Earth-2 (EASE-2) grid, or $30 \times 30$ GOES LST cells at $0.05^{\circ}$ resolution. This area is chosen because of the relatively 


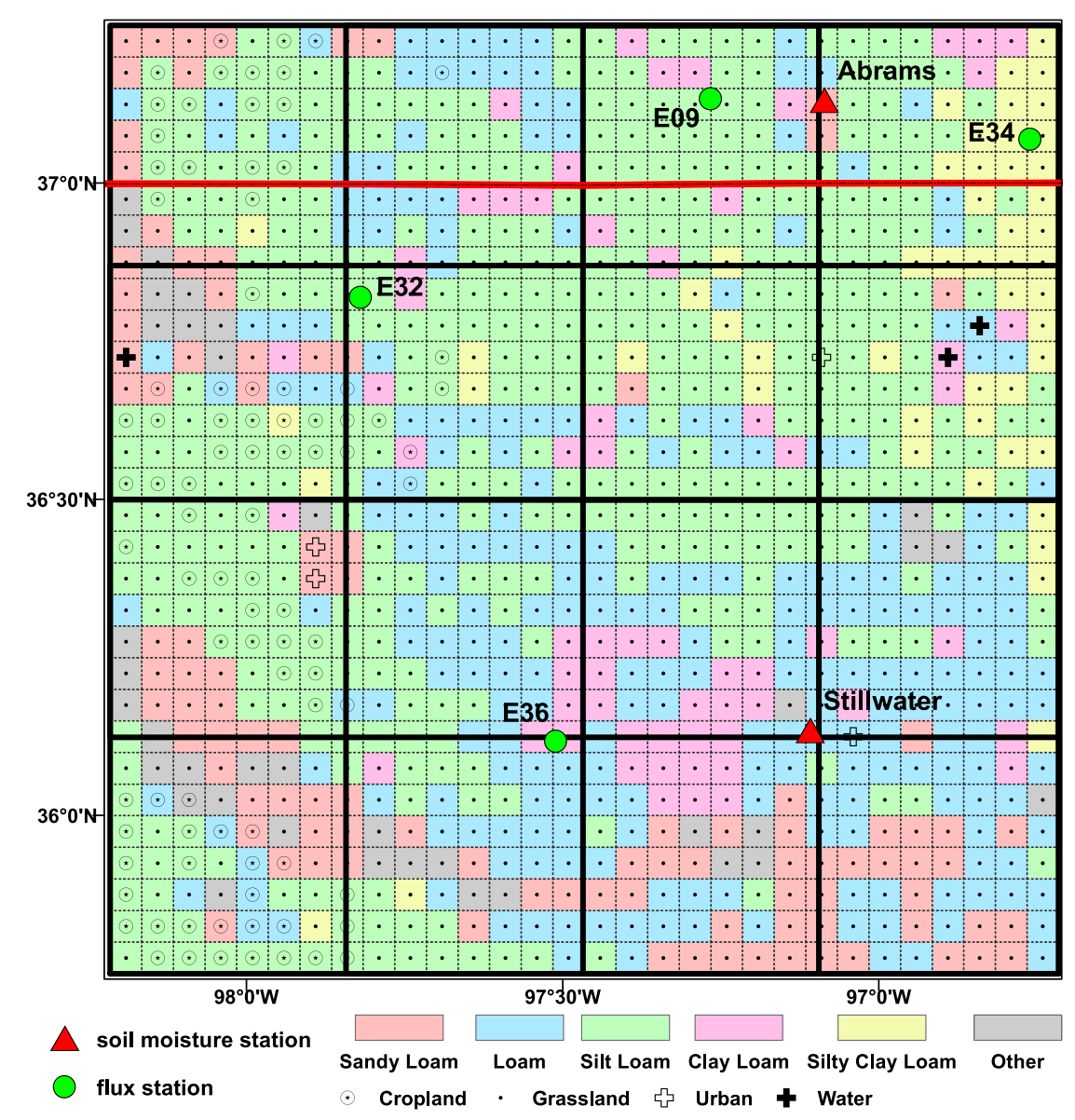

FIG. 1. Study area with stations and dominant soil types and land cover for each pixel. The SMAP grid cells are represented by the thick black lines, and the GOES grid cells are demonstrated by the thin dashed lines. The border between Kansas to the north and Oklahoma to the south is plotted in a red line.

dense flux network. The area is flat and mostly covered by grassland and cropland, with a small fraction of urban area and water bodies. The dominant soil types are sandy loam and silt loam, as shown in Fig. 1. In situ flux measurements are available at four stations from the Atmospheric Radiation Measurement (ARM) network. Sensible $(H)$ and latent (LE) heat flux measurements are provided every $30 \mathrm{~min}$ by energy balance Bowen ratio (EBBR) instruments. In situ soil moisture observations are available at two stations (Stillwater and Abrams) from the U.S. Climate Reference Network (CRN; Bell et al. 2013) and the Soil Climate Analysis Network (SCAN; Schaefer et al. 2007), respectively. The data are collected hourly at the depths of 5, 10, 20, 50, and $100 \mathrm{~cm}$ from the surface.

Input data can be categorized into forcing data, ancillary data, and data for assimilation. Precipitation forcing data are obtained from the 3IMERGHH product provided by the Global Precipitation Mission (GPM)
(Hou et al. 2014). The data are provided at 30-min time interval and $0.1^{\circ}$ spatial resolution (Huffman et al. 2015). The atmospheric forcing data, including incoming shortwave $R_{s}^{\downarrow}$ and longwave radiation $R_{l}^{\downarrow}$, wind speed $U$, air temperature $T_{a}$, and air pressure $P_{a}$ come from the North American Land Data Assimilation System project phase 2 (NLDAS-2) (Xia et al. 2012). The data are provided hourly at $0.125^{\circ}$ resolution. Since the forcing data are coarser than the model grid cell, a "drop in the bucket" strategy is used to extract forcing data for each model grid cell (i.e., the forcing data from the single GPM/NLDAS-2 grid cell closest to, or overlaying, the model grid cell are used).

The ancillary data used in this study include soil texture, vegetation, and land cover data. The soil texture data, including soil sand fraction, soil clay fraction, and soil bulk density data are provided on a 3-km EASE-2 grid by the National Snow and Ice Data Center (NSIDC) (Das 2013), which are also used for SMAP soil moisture 
retrieval. This is to make the forward modeling of TB consistent with SMAP soil moisture retrieval and to avoid influences from differences in soil texture ancillary data. Soil hydraulic properties are computed based on texture information using the ROSETTA software (Schaap et al. 2001). The vegetation data, including the normalized difference vegetation index (NDVI) and the leaf area index (LAI) data are obtained from the Moderate Resolution Imaging Spectroradiometer (MODIS) MOD13C1 and MCD15A2 products, respectively. The NDVI data are available at $0.05^{\circ}$ resolution every 16 days (Huete et al. 1999), while the LAI data are provided every 8 days at $1-\mathrm{km}$ resolution (Knyazikhin et al. 1999). The land cover data are from ESA Climate Change Initiative (CCI) (v1.6.1). All ancillary data are spatially regridded to the resolution of model grid cells $\left(0.05^{\circ}\right)$. Since no daily LAI or NDVI data are available, the datasets are also linearly interpolated between two observation dates to generate daily values (Abdolghafoorian et al. 2017; Lu et al. 2017). Previous studies suggest that linear interpolation provides reasonable approximation of the daily value (Houborg et al. 2016). Although the LAI and NDVI datasets are spatially and temporally gap-free in this study, it is worth noting that linear interpolation generally performs poorly in case of long periods without observations (Kandasamy et al. 2013).

The TB data for assimilation are the SMAP Level-1C (L1C_TB) data acquired by the L-band radiometer at 2-3-day intervals (Entekhabi et al. 2014). The TB observations are the arithmetic average of the fore- and aft-looking TB data obtained from https://reverb.echo.nasa.gov/ and are only assimilated at 0600 LT (descending node), when the temperature within one model grid cell is very homogeneous, and the vegetation temperature can be assumed the same as soil temperature. The GOES LST data are acquired from the Copernicus Global Land Service (available from http://land.copernicus.eu/global). The dataset is based on fusion of multisource infrared sensors and provided hourly at $0.05^{\circ}$ resolution. The datasets are summarized in Table 1, and all datasets are processed and mapped to geographic coordinates. The assimilation period covers two growing seasons, that is, day of year (DOY) 91 through DOY 304 (April-October) for 2015 and 2016, respectively.

\section{b. Model framework}

\section{1) DUAL-SOURCE MODEL}

The dual-source model scheme introduced by Lu et al. (2017) is used, which is based on surface energy balance. In the dual-source scheme, the contributions to the energy fluxes from both soil and vegetation are characterized, and their energy balance is constructed separately.
TABLE 1. Summary of datasets. The variables are explained in the text.

\begin{tabular}{lllcc}
\hline \hline \multirow{2}{*}{ Category } & Source & \multicolumn{1}{c}{ Dataset } & \multicolumn{2}{c}{$\begin{array}{c}\text { Original } \\
\text { resolution }\end{array}$} \\
\cline { 3 - 5 } Forcing & NLDAS-2 & $R_{s}^{\downarrow}, R_{l}^{\downarrow}, U, T_{a}, P_{a}$ & $0.125^{\circ}$ & $1 \mathrm{~h}$ \\
& GPM & $P$ & $0.1^{\circ}$ & $30 \mathrm{~min}$ \\
Ancillary & NSIDC & Soil texture & $3 \mathrm{~km}$ & - \\
& MODIS & LAI & $1 \mathrm{~km}$ & 8 days \\
& & NDVI & $0.05^{\circ}$ & 16 days \\
Assimilation & ESA CCI & Land cover & $300 \mathrm{~m}$ & - \\
& SMAP & TB & $36 \mathrm{~km}$ & $2-3$ days \\
& GOES & LST & $0.05^{\circ}$ & $1 \mathrm{~h}$ \\
\hline
\end{tabular}

The total $H$ can be derived by

$$
H=\rho C_{p} U\left(T_{w}-T_{a}\right) C_{H},
$$

where $\rho\left(\mathrm{kg} \mathrm{m}^{-3}\right)$ is air density, $C_{p}\left(\mathrm{~J} \mathrm{~kg}^{-1} \mathrm{~K}^{-1}\right)$ is specific heat capacity of air, $U\left(\mathrm{~m} \mathrm{~s}^{-1}\right)$ is wind speed at a reference height above the canopy, $T_{w}(\mathrm{~K})$ and $T_{a}(\mathrm{~K})$ are the air temperature within and above the canopy, and $C_{H}(-)$ is $C_{H N}(-)$ modified for atmospheric instability.

Following Farhadi et al. (2014), $C_{H N}$ can be estimated from LAI by

$$
C_{H N}=\exp (a+b \times \mathrm{LAI}) .
$$

Here $a$ and $b$ are two parameters to be estimated. By assuming an exponential decay of conductance within the canopy (Caparrini et al. 2004b), the influence of $C_{H N}$ for the fluxes over soil and canopy can be evaluated. This relationship is shown to be valid under a wide range of LAI values (Abdolghafoorian et al. 2017).

When $H$ is calculated, LE can be derived using the EF. In the dual-source scheme, EF (-) for soil $\left(\mathrm{EF}_{s}\right)$ and canopy $\left(\mathrm{EF}_{c}\right)$ are calculated separately and assumed constant during the daytime window (0900-1600 LT) under clear-sky conditions. Hence only one $\mathrm{EF}_{s}$ and one $\mathrm{EF}_{c}$ need to be estimated each day, making the application easier and more robust (Caparrini et al. 2004a). This assumption has been tested in many studies (Crago 1996; Crago and Brutsaert 1996; Gentine et al. 2007) and has been proven effective in surface heat flux estimation.

The state propagation model consists of a coupled heat transfer module and a water transfer module. The modeled temperature impacts the magnitude of $H$ and hence LE, which serves as the sink term in soil moisture simulation, while the modeled soil moisture influences surface energy partitioning through EF and further determines the ground heat flux which propagates the heat transfer process. 
The heat transfer is modeled using the forcerestore model

$$
\frac{d T_{s}}{d t}=\frac{2 \sqrt{\pi \omega}}{P_{e}} G-2 \pi \omega\left(T_{s}-T_{d}\right)+\varepsilon,
$$

where $P_{e}\left(\mathrm{~J} \mathrm{~m}^{-2} \mathrm{~K}^{-1} \mathrm{~s}^{-1 / 2}\right)$ is the effective thermal inertia, $G\left(\mathrm{~W} \mathrm{~m}^{-2}\right)$ is ground heat flux, $\omega\left(\mathrm{s}^{-1}\right)$ is the diurnal frequency, $T_{s}(\mathrm{~K})$ is soil temperature, $T_{d}(\mathrm{~K})$ is deep ground temperature, and $\varepsilon$ represents model error. The $P_{e}$ term is calculated from soil moisture, bulk density, and sand fraction ( $\mathrm{Lu}$ et al. 2009), and $T_{d}$ is estimated with a semidiurnal filter of surface temperature (Caparrini et al. 2003).

The water transfer is modeled using a similar scheme used in the Simple Biosphere model (SiB) (Sellers et al. 1986),

$$
\left\{\begin{array}{l}
\frac{\partial W_{1}}{\partial t}=\frac{1}{\theta_{s} D_{1}}\left[I_{1}-Q_{1,2}-\frac{1}{\rho_{w}}\left(E_{s}+E_{t, 1}\right)\right] \\
\frac{\partial W_{k}}{\partial t}=\frac{1}{\theta_{s} D_{k}}\left(Q_{k-1, k}-Q_{k, k+1}-\frac{1}{\rho_{w}} E_{t, k}\right), \quad k=2, \ldots, n-1, \\
\frac{\partial W_{n}}{\partial t}=\frac{1}{\theta_{s} D_{n}}\left(Q_{n-1, n}-Q_{n}\right)
\end{array}\right.
$$

where $n$ is the number of soil layers, $W_{k}(-)$ is the soil wetness of the $k$ th layer, $\theta_{s}\left(\mathrm{~m}^{3} \mathrm{~m}^{-3}\right)$ is soil moisture at saturation, $I_{1}\left(\mathrm{~cm} \mathrm{~s}^{-1}\right)$ is the infiltration into the first layer from precipitation, $D_{k}(\mathrm{~cm})$ is the thickness of the $k$ th layer, $Q_{k, k+1}\left(\mathrm{~cm} \mathrm{~s}^{-1}\right)$ is the flow between the $k$ th and $k+1$ th layer, $\rho_{w}\left(\mathrm{~g} \mathrm{~cm}^{-3}\right)$ is water density, $E_{s}\left(\mathrm{~g} \mathrm{~cm}^{-2} \mathrm{~s}^{-1}\right)$ is the water loss from soil evaporation, $E_{t, k}\left(\mathrm{~g} \mathrm{~cm}^{-2} \mathrm{~s}^{-1}\right)$ is the water loss from vegetation transpiration in the $k$ th layer, and $Q_{n}\left(\mathrm{~cm} \mathrm{~s}^{-1}\right)$ is the gravitational drainage from the bottom layer.

In this study a $90-\mathrm{cm}$ soil column is used, which is divided into six layers with thicknesses of $5,10,15,15$, 15 , and $30 \mathrm{~cm}$, respectively. The modeled soil moisture is then used to get a prior estimate of $\mathrm{EF}_{s}$ and $\mathrm{EF}_{c}$ using an improved arctangent-form relationship first proposed by Dirmeyer et al. (2000). A detailed description of the model implementation can be found in Lu et al. (2017).

\section{2) RADiATIVE TRANSFER MODEL (RTM)}

To assimilate SMAP TB observations, the state propagation model is coupled to a RTM to generate TB simulations. The RTM used in this study mimics the RTM used in the SMAP Level-2 retrieval algorithm (O'Neill et al. 2015). This model is developed by Jackson (1993) based on the $\tau-\omega$ model and calculates TB in both horizontal $\left(\mathrm{TB}_{H}\right)$ and vertical $\left(\mathrm{TB}_{V}\right)$ polarization. The real part of soil dielectric constant $\varepsilon_{r}$ is first calculated from soil moisture using a dielectric model. Here the model proposed by Mironov et al. (2009) is used for its simplicity over other models (Wang and Schmugge 1980; Dobson et al. 1985). The smooth surface soil emissivity $e_{\text {soil_s }}$ is calculated from the dielectric constant using the Fresnel equation. For horizontal polarization, $e_{\text {soil_s }}$ is calculated by

$$
e_{\text {soil_s }}=1-\left|\frac{\cos \eta-\sqrt{\varepsilon_{r}-\sin ^{2} \eta}}{\cos \eta+\sqrt{\varepsilon_{r}-\sin ^{2} \eta}}\right|^{2},
$$

where $\eta$ is the incidence angle, which is $40^{\circ}$ for the SMAP radiometer.

For vertical polarization, $e_{\text {soil_s }}$ is calculated by

$$
e_{\text {soil_s }}=1-\left|\frac{\varepsilon_{r} \cos \eta-\sqrt{\varepsilon_{r}-\sin ^{2} \eta}}{\varepsilon_{r} \cos \eta+\sqrt{\varepsilon_{r}-\sin ^{2} \eta}}\right|^{2} .
$$

The influence of surface roughness (Choudhury et al. 1979) is then included to derive the rough surface soil emissivity $e_{\text {soil_} \_r}$ by

$$
e_{\text {soil_ } r}=1-\frac{1-e_{\text {soil_s }}}{\exp \left(h_{r} \cos ^{2} \eta\right)},
$$

where $h_{r}$ is a parameter dependent on the polarization, frequency, and surface geometric properties (Entekhabi et al. 2014).

Further, vegetation influence is included to derive the land surface emissivity $e_{\text {surf }}$ (O'Neill et al. 2015):

$e_{\text {surf }}=\left(1-\omega_{s}\right)(1-\gamma)\left[1+\left(1-e_{\text {soil_r }}\right) \gamma\right]+e_{\text {soil_ } r} \gamma$.

Here $\omega_{s}(-)$ is the scattering albedo, and $\gamma(-)$ is the oneway transmissivity of the canopy, which is estimated from the vegetation water content (VWC)-based optical depth $\tau$ :

$$
\gamma=\exp (-\tau \sec \eta)=\exp \left(-b_{v} \times \mathrm{VWC} \times \sec \eta\right) .
$$

The values for $h_{r}, \omega_{s}$, and $b_{v}$ are taken from a lookup table provided in O'Neill et al. (2015), and VWC is 
calculated from the actual NDVI, the annual maximum NDVI, and a land-cover-dependent stem factor using a lookup table (O'Neill et al. 2015).

$\mathrm{TB}$ of the land surface $\left(\mathrm{TB}_{\text {land }}\right)$ is given based on the Rayleigh-Jeans approximation by

$$
\mathrm{TB}_{\text {land }}=e_{\text {surf }} T_{\text {eff }}
$$

where $T_{\text {eff }}(\mathrm{K})$ is the effective temperature of the land surface, which is a measure of the contribution of the whole soil column to microwave emission (O'Neill et al. 2015). In many studies, $T_{\text {eff }}$ is estimated as a weighted average of the surface $(0-5 \mathrm{~cm})$ and deeper ground temperature $(50-100 \mathrm{~cm})$ (Choudhury et al. 1982; Wigneron et al. 2001, 2008; Holmes et al. 2006). Here the method proposed by Wigneron et al. (2008) is adopted, which includes the influence of soil moisture on the weights. TB simulations are performed at the model resolution of $0.05^{\circ}$ and then aggregated to the SMAP TB grid scale $(36 \mathrm{~km})$ using a simple arithmetic averaging.

Water bodies within a SMAP cell dramatically lower the TB observations, and need to be accounted for in the forward modeling. Here $\mathrm{TB}_{\text {water }}$ is derived using a theoretical model proposed by Klein and Swift (1977). The simulated $\mathrm{TB}$ observations $\left(\mathrm{TB}_{\mathrm{sim}}\right)$ are then calculated as a weighted average of $\mathrm{TB}_{\text {land }}$ and $\mathrm{TB}_{\text {water: }}$ :

$$
\mathrm{TB}_{\text {sim }}=f_{\text {water }} \mathrm{TB}_{\text {water }}+\left(1-f_{\text {water }}\right) \mathrm{TB}_{\text {land }},
$$

where $f_{\text {water }}$ is the water fraction in the model cell.

Since the theoretical modeling of TB of man-made, impervious, and urban areas is very difficult with the present land surface scheme (O'Neill et al. 2015), the urban fraction within model grid cells is treated in the following way: 1) If urban area is not the dominant land cover type of the cell, the cell is considered nonurban and the influence from urban area is assumed marginal and ignored. 2) Otherwise, the $\mathrm{TB}_{\text {sim }}$ is not calculated, and the grid cell is excluded (i.e., masked out) from the spatial aggregation to the $36-\mathrm{km}$ SMAP TB simulations.

\section{c. Assimilation strategy}

Similar to the case in Lu et al. (2017), the SMAP data (TB or soil moisture) are assimilated with a particle filter, whereas the GOES LST data are assimilated with a particle smoother. The main reason for using this hybrid assimilation strategy is the large difference in spatial and temporal resolution of the SMAP and GOES data. Since GOES LST data are much finer than SMAP TB data both spatially and temporally, the information contained in the SMAP TB observations will be swamped by the large number of GOES LST observations if assimilated simultaneously in one batch. In addition, the SMAP TB observations are a "snapshot" of the instantaneous land surface states, and only available every $2-3$ days, which limits their ability to constrain the temporal dynamics or the model trajectory of soil moisture (Dunne and Entekhabi 2006). A filter is therefore better suited to update the instantaneous soil moisture state at the satellite overpass time, and since soil moisture has inherent memory, the update will propagate naturally in time. Related to the LST observations, surface energy partitioning affects not only the magnitude, but to a much larger extent in the temporal evolution of LST time series. A batch smoother is thus more appropriate to extract information from a series of frequently sampled LST observations.

Here the SMAP TB observations are assimilated using the particle filter (PF) at SMAP descending overpass time (0600 LT) to update soil moisture. Next, all available GOES LST data in the daytime assimilation window (0900-1600 LT) are assimilated with an adaptive particle batch smoother (APBS) at 1600 LT to update LST as well as four selected parameters: $a$ and $b$ for estimating $C_{H N}$, and two slope parameters $\left(\alpha_{s}\right.$ and $\left.\alpha_{c}\right)$ to estimate $\mathrm{EF}_{s}$ and $\mathrm{EF}_{c}$. Here the TB assimilation does not update soil temperature, and the LST assimilation does not update soil moisture. However, an integrated soil moisture and temperature update is possible and may be considered for future research.

\section{1) PARTiCle Filter}

Particle filters originate from Bayesian theory (Moradkhani et al. 2005). Unlike Kalman filter-based methods that directly update model states, the PFs use a likelihood function to calculate and update the weights of particles (Dong et al. 2015; Moradkhani et al. 2012; Yan et al. 2015).

The observation is related to the true state by

$$
\mathbf{y}_{t}=h\left(\mathbf{x}_{t}\right)+\mathbf{v}_{t},
$$

where $\mathbf{y}_{t}$ is the observation at time step $t, \mathbf{x}_{t}$ is the state vector, $h$ represents the observation operator that maps the state (geophysical) space into observation space, and $\mathbf{v}_{t}$ is the observation error. The state vector here consists of soil moisture of each layer in the soil column, while the observation operator consists of the RTM as well as spatial averaging.

Uniform weights are given to the particles at first. When assimilation is conducted, the particle weights are updated by

$$
\begin{gathered}
w_{t}^{i *} \propto w_{t-1}^{i} p\left(\mathbf{y}_{t} \mid \mathbf{x}_{t}^{i}\right), \\
w_{t}^{i}=\frac{w_{t}^{i *}}{\sum_{i=1}^{N} w_{t}^{i^{*}}}
\end{gathered}
$$


where $w_{t}^{i *}$ is the unnormalized weight of the $i$ th particle from importance sampling, $w_{t}^{i}$ stands for the weight after normalization, $N$ is particle size, and $p\left(\mathbf{y}_{t} \mid \mathbf{x}_{t}^{i}\right)$ is the likelihood function, which is given by (Dong et al. 2015)

$$
p\left(\mathbf{y}_{t} \mid \mathbf{x}_{t}^{i}\right) \propto \exp \left[-0.5\left(\mathbf{y}_{t}-\hat{\mathbf{y}}_{t}^{i}\right)^{\mathrm{T}} \mathbf{R}^{-1}\left(\mathbf{y}_{t}-\hat{\mathbf{y}}_{t}^{i}\right)\right] .
$$

Here $\hat{\mathbf{y}}_{t}^{i}$ is the simulated observation, and $\mathbf{R}$ is the observation error covariance (scalar variance in this case). The SMAP TB filtering uses one coarse observation to update all $0.05^{\circ}$ state variables in the footprint.

\section{2) TB AsSimilation}

At SMAP descending overpass time (0600 LT), SMAP TB observations are assimilated using the PF if available. Since the model grid cells have a finer resolution, an averaging operator is adopted to convert the RTM-derived TB at $0.05^{\circ}$ model grid cell to the simulated TB at $36-\mathrm{km}$ scale. For that purpose, first all nonurban model grid cells in one SMAP TB grid cell are identified. Second, for each nonurban model grid cell the particles are sorted by their simulated TB, which serves as the basis for updating particles in the assimilation procedure. This is to ensure that spatial patterns simulated by the model are retained in the updated states. Here it is assumed that the first particle yields the highest TB, while the last particle has the lowest TB. Finally, for all nonurban model grid cells the particles are grouped by their respective ranking (i.e., the first group contains all the first ranked particles from each of the model grid cells). The simulated TB observation for each group is then estimated as the algebraic average of all members:

$$
\hat{\mathbf{y}}_{t}^{i}=\frac{\sum_{j=1}^{M} \mathrm{~TB}_{j, t}^{i}}{M} .
$$

Here $M$ stands for the total number of nonurban model grid cells within one SMAP grid cell, $\mathrm{TB}_{j, t}^{i}$ is the TB simulation of the $i$ th particle in $j$ th model grid cell at time step $t$. Here $\hat{\mathbf{y}}_{t}^{i}$ is derived at the $36-\mathrm{km}$ SMAP TB scale. During assimilation, the likelihood of each particle group is calculated using Eq. (15). Soil moisture of the entire soil column is then updated based on the likelihood to maintain water balance and the consistency between layers within one particle.

TB observation error consists of instrument error and representativeness error. The instrument error for SMAP radiometer is anticipated to be around $1.3 \mathrm{~K}$ at $36-\mathrm{km}$ scale (Reichle et al. 2012; Das et al. 2016). The representativeness error is composed of RTM errors resulted from imperfect model structure, suboptimal parameters or ancillary data (e.g., vegetation, soil), and the spatial and temporal mismatch error between TB observations and model simulations. The representativeness error for SMAP TB data is assumed similar to that of SMOS TB data, since both missions operate in L-band and provide TB observations at similar spatial scales. The representativeness error depends on soil moisture and LST and should ideally be modeled online in the assimilation system. Here a constant representativeness error of $4.5 \mathrm{~K}$ is adopted following De Lannoy and Reichle (2016a) for simplicity. The observation error is then assumed to be $5 \mathrm{~K}\left(5 \approx \sqrt{1.3^{2}+4.5^{2}}\right)$ for both horizontal and vertical polarizations and spatially and temporally uncorrelated.

\section{3) AdAPTIVE PARTICLE BATCH SMOOTHER (APBS)}

The particle batch smoother (PBS) was first developed by Dong et al. (2015) and by Margulis et al. (2015) independently, which was further improved by Dong et al. (2016b) into the APBS. The main difference between a filter and a batch smoother is that the filter assimilates observations sequentially, while the batch smoother assimilates all available observations within a window in a batch. The limitation of the PBS is the requirement to calibrate a tuning factor to avoid particle degeneracy, which is improved in the APBS with an adaptive calibration strategy.

In the APBS, the likelihood function is given by

$$
\begin{aligned}
& p\left(\mathbf{y}_{t-L+1: t} \mid \mathbf{x}_{t-L+1: t}^{i}\right) \propto \prod_{j=t-L+1}^{t} \exp \left[-0.5 \beta^{2}\left(\mathbf{y}_{j}-\hat{\mathbf{y}}_{j}^{i}\right)^{\mathrm{T}}\right. \\
& \left.\quad \times \mathbf{R}^{-1}\left(\mathbf{y}_{j}-\hat{\mathbf{y}}_{j}^{i}\right)\right] .
\end{aligned}
$$

Here $L$ is the length of the assimilation window, $\mathbf{R}$ is the error covariance matrix of observations, and $\beta$ is a tuning factor to avoid particle degeneracy (Dong et al. 2016a). The tuning factor $\beta$ varies between 0 and 1 and is determined by maximizing the reliability of state estimates.

\section{4) LST ASSIMILATION}

GOES LST observations are related to the modeled soil temperature $T_{s}$ and vegetation temperature $T_{c}$ following Kustas et al. (1996):

$$
\mathrm{LST}=\left[f_{c} T_{c}^{4}+\left(1-f_{c}\right) T_{s}^{4}\right]^{1 / 4} .
$$

Here $f_{c}$ is the vegetation cover fraction calculated from LAI. The temporal autocorrelations among LST observation errors are not addressed for simplicity. The LST data assimilation is conducted if at least four observations (out of a maximum of eight in the window) are available in the daytime assimilation window, and a 
3-K observation error is assumed (Lu et al. 2017). During assimilation, the state vector is augmented as follows

$$
\mathbf{X}=\left[\operatorname{LST}_{t_{1}} \operatorname{LST}_{t_{2}} \cdots \operatorname{LST}_{t_{m}} a b \alpha_{s} \alpha_{c}\right]
$$

where $t_{1}, t_{2}, \ldots, t_{m}$ are the time steps within the daytime window when GOES LST observations are available at a certain model grid cell; $a$ and $b$ are the parameters for $C_{H N}$ estimation; and $\alpha_{s}$ and $\alpha_{c}$ are the slope factors for $\mathrm{EF}_{s}$ and $\mathrm{EF}_{c}$ estimation.

\section{d. Bias correction}

An assumption for most data assimilation systems is unbiased observations and forecasts. However, the remote sensing observations and the model simulations often reveal different climatologies, in terms of longterm mean or variability (Reichle and Koster 2004; Reichle et al. 2004). This may be caused by the limitations of the model (e.g., imperfect structure, simplifications, suboptimal parameters) (De Lannoy et al. 2007) or nonuniform representation of land surface variables of the remote sensing system [e.g., shallower $(<5 \mathrm{~cm})$ observed depth of soil moisture] (Sahoo et al. 2013), among others. The difference in climatology can be even more dramatic for TB observations (Kornelsen et al. 2015). A common practice is to correct for the bias prior to data assimilation. Generally, bias correction methods focus on correction of the first-order moment (the long-term mean) (Sahoo et al. 2013; De Lannoy and Reichle 2016b,a), the first two moments (mean and standard deviation) (Crow et al. 2005; Kumar et al. 2012), or higher moments [the distribution, often through cumulative distribution function (CDF) matching] (Reichle and Koster 2004; Lievens et al. 2016). More sophisticated methods have also been proposed (Yilmaz and Crow 2013; Kornelsen and Coulibaly 2015; Su and Ryu 2015). There is not a simple "optimal" bias correction method for a large range of applications, and the appropriate bias correction scheme is application dependent.

A seasonal bias correction approach is used here to correct for the bias in TB observations. Lu et al. (2017) used CDF matching to correct for the bias in SMAP soil moisture since the bias in soil moisture is stationary and less season dependent. In contrast, despite the dependence on soil moisture, the magnitude of TB is also strongly influenced by $T_{\text {eff }}$ and vegetation patterns. The bias in TB hence varies with season, since both $T_{\text {eff }}$ and vegetation have a strong seasonal cycle. Therefore the seasonally varying difference between SMAP TB observations and ensemble mean TB simulations is corrected.

Here bias correction is not performed for LST data. First, LST data retrieved from the GOES mission have proved accurate without significant bias compared with
TABLE 2. Perturbations for the forcing data, where $\times$ and + represent multiplicative and additive perturbations, respectively.

\begin{tabular}{clc}
\hline \hline Forcing & Perturbation & Standard deviation \\
\hline$R_{s}^{\downarrow}$ & Gaussian, $\times$ & $\times, 0.1$ \\
$R_{l}^{\downarrow}$ & Gaussian, $\times$ & $\times, 0.1$ \\
$U$ & Gaussian, + & $1 \mathrm{~m} \mathrm{~s}^{-1}$ \\
$T_{a}$ & Gaussian, + & $5 \mathrm{~K}$ \\
$P$ & Lognormal, $\times$ & $\times, 0.2$ \\
\hline
\end{tabular}

ground measurements (Sun and Pinker 2003; Pinker et al. 2009). Second, the particle smoother will reduce the difference between model simulated LST and GOES observations by adjusting the parameter values to make model simulations match observation climatology. The impact on estimated surface heat fluxes is expected to be small as long as the parameter ranges are within a physically reasonable range (Lu et al. 2017). Note that earlier LST assimilation studies using a Kalman filter for state updating only (no parameter updating) were in need of bias estimation (Reichle et al. 2010; Draper et al. 2015).

The bias correction steps are conducted for $\mathrm{TB}_{H}$ and $\mathrm{TB}_{V}$ separately. Since SMAP TB observations are coarser than model simulations, the simulated TB is derived by averaging all nonurban modeled TB from model grid cells that fall into each SMAP cell. To this end, we first calculate the ensemble mean of modeled TB for each nonurban model grid cell at each SMAP descending overpass time. Then a 30-day moving window is used, which averages the time series of SMAP TB observations as well as simulated TB forecasts for each SMAP grid cell separately. Finally, the differences between window-mean SMAP TB observations and model simulations are removed from SMAP minus simulated TB innovations, and only shortterm differences between observations and forecasts are assimilated.

\section{e. Experiment setup}

At 0000 on the first day of model simulation, the soil profile is assumed uniform and initialized randomly within the physically valid range defined by the saturated and residual soil moisture. The land surface temperature is initialized using GOES observations within a 5-K range. For each experiment, 600 particles are used, and the states are modeled at $0.05^{\circ}$ resolution every $30 \mathrm{~min}$. The perturbations used are summarized in Table 2. The perturbations have been used in Lu et al. (2017) and proved reasonable.

The initial parameter ranges are given to $a(-7<a<-5)$ and $b(0<b<1)$ based on Abdolghafoorian et al. (2017). An initial range of $(1,10)$ is used for $\alpha_{s}$ and $\alpha_{c}$ 

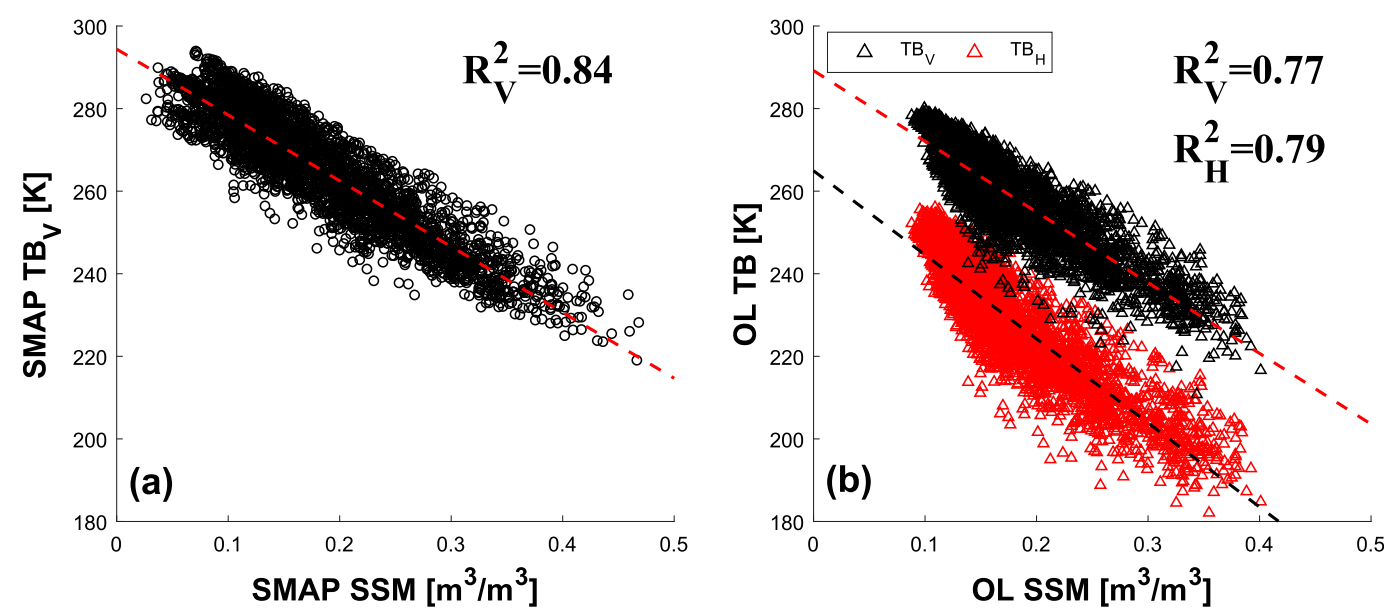

FIG. 2. Correlations between TB and surface soil moisture (SSM) from (a) SMAP (L1C_TB and Level-3 SSM) and (b) OL simulations in the study period. The data pairs are extracted from all descending overpass time in the study period in all the 16 SMAP TB grid cells.

based on the values reported by Dirmeyer et al. (2000). These ranges have proved reasonable in $\mathrm{Lu}$ et al. (2017).

During the daytime window, $T_{s}$ and $T_{c}$ are propagated to calculate $H$. LE is then estimated using $\mathrm{EF}_{s}$ and $\mathrm{EF}_{c}$. The term $G$ is calculated as the residual of the surface energy balance. Outside the daytime window, $G$ is estimated as a fraction of the net radiation to propagate temperatures, since EF can no longer be assumed constant. More details can be found in Lu et al. (2016).

The flux estimation similarities between different assimilation strategies are assessed over the study area using the Kling-Gupta efficiency (KGE; Gupta et al. 2009). The KGE is expressed as

$$
\mathrm{KGE}=1-\sqrt{(r-1)^{2}+\left(\frac{\sigma_{\mathrm{ts} 1}}{\sigma_{\mathrm{ts} 2}}-1\right)^{2}+\left(\frac{\mu_{\mathrm{ts} 1}}{\mu_{\mathrm{ts} 2}}-1\right)^{2}},
$$

where $r$ is the correlation coefficient between two surface heat flux time series, $\sigma_{\mathrm{ts} 1}$ and $\sigma_{\mathrm{ts} 2}$ are the standard deviation of the two time series, while $\mu_{\mathrm{ts} 1}$ and $\mu_{\mathrm{ts} 2}$ are the corresponding mean values. KGE ranges from minus infinity (poor agreement) to unity (perfect agreement).

\section{Results and discussion}

\section{a. Open-loop simulations}

Figure 2 compares the spatiotemporal correlations between the $36-\mathrm{km}$ TB and surface soil moisture $(0-5 \mathrm{~cm}$, hereafter SSM) for SMAP products and open-loop (no assimilation case, hereafter OL) simulations in the whole study period (2015 and 2016 combined). Since the Level-3 SMAP soil moisture product is retrieved from vertically polarized TB observations using the single channel algorithm (SCA) algorithm (O'Neill et al. 2015), only $\mathrm{TB}_{V}$ is included in the SMAP analysis. The correlations between TB and SSM are generally very high, indicating a strong control of SSM on TB. For vertical polarization, SMAP $\mathrm{TB}_{V}$ observations are slightly higher than $\mathrm{OL}$ modeled $\mathrm{TB}_{V}$ and have a larger dynamic range. This may be caused by the difference between the SMAP sensing depth and model settings. Studies have shown that SMAP may measure shallower soil moisture than the nominal 5-cm depth (Shellito et al. 2016). The correlation between $\mathrm{TB}_{V}$ and SSM is lower for OL simulations than for SMAP data. This is mainly caused by differences in the ancillary datasets used for the operational retrieval and the forward simulation. Results from 2015 and 2016 show similar patterns, while the correlations for the 2016 study period are generally lower for both the SMAP data $\left(R_{V}^{2}=0.85\right)$ and the model simulations $\left(R_{V}^{2}=0.73\right.$, $\left.R_{H}^{2}=0.78\right)$ compared to the 2015 study period $\left(R_{V}^{2}=0.91\right.$ for SMAP data, $R_{V}^{2}=0.81, R_{H}^{2}=0.80$ for model simulations). This relates to the drier condition in 2016, when the mean total precipitation during the study period $(723 \mathrm{~mm})$ is over $100 \mathrm{~mm}$ less than in 2015 ( $829 \mathrm{~mm})$. The soil emissivity becomes more variant for dry soil than for wet soil (Njoku and Entekhabi 1996), which decreases the correlation between SSM and TB.

The statistical metrics measuring the temporal agreement between SMAP observations and OL simulations are provided in Fig. 3 for both $\mathrm{TB}_{H}$ and $\mathrm{TB}_{V}$ (top row). The boxplots show the distribution of the statistics calculated for the 16 SMAP grid cells. OL simulated $\mathrm{TB}_{V}$ is better correlated with SMAP observations than 

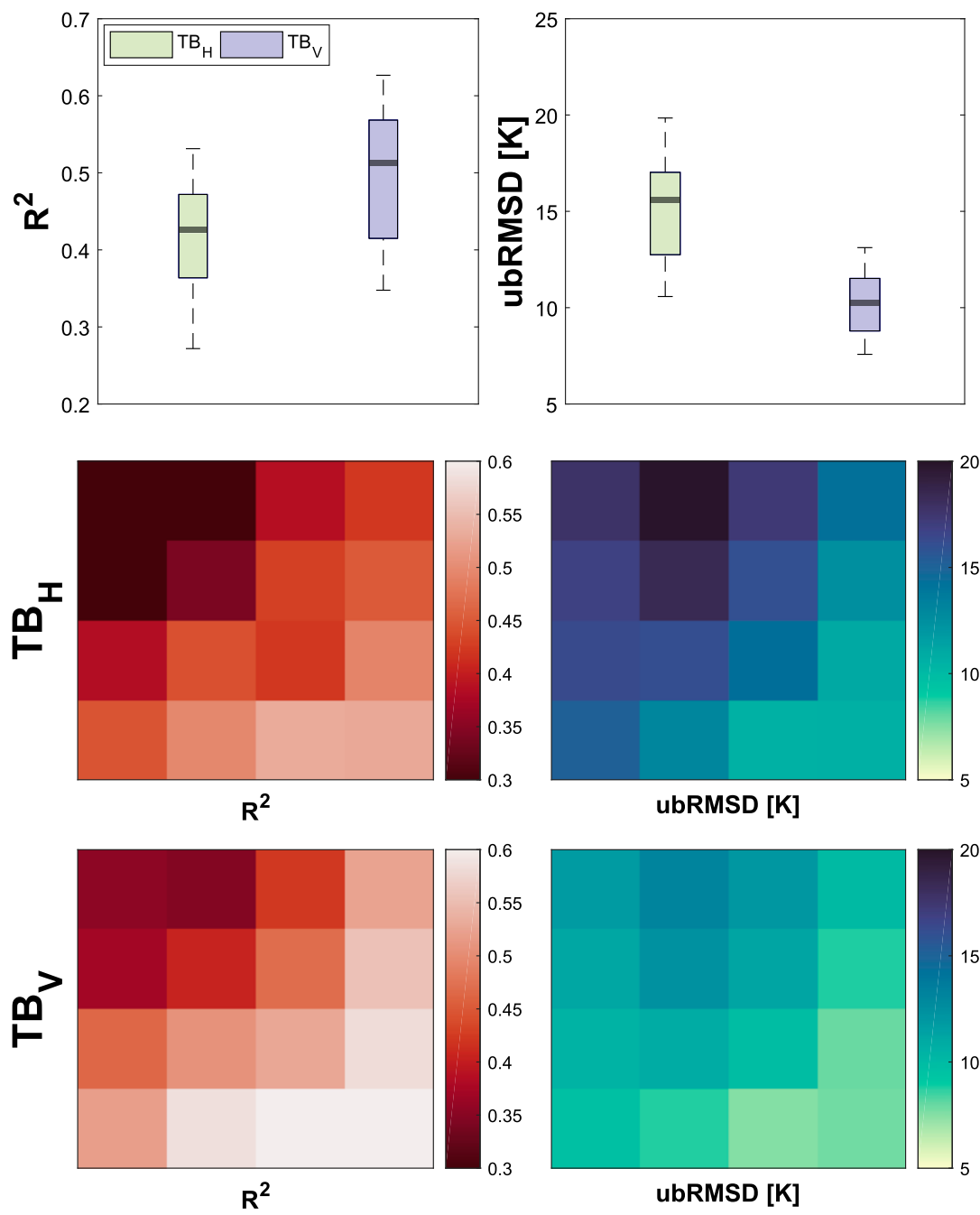

ubRMSD [K]
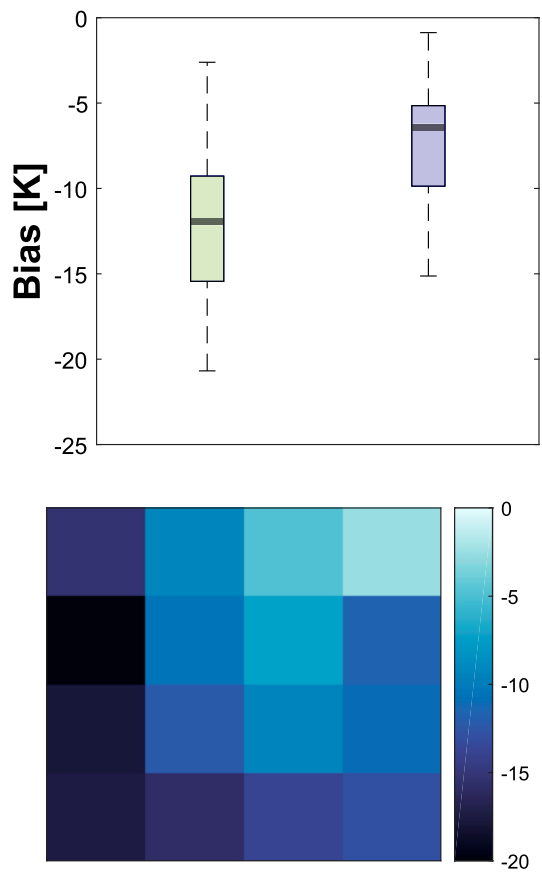

Bias [K]

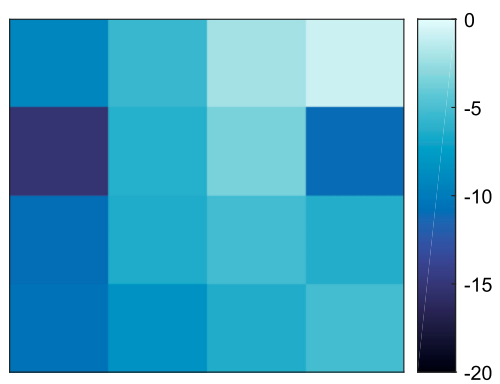

Bias $[K]$

FIG. 3. Statistical metrics between SMAP observations and OL simulations for $\mathrm{TB}_{H}$ and $\mathrm{TB}_{V}$ and their spatial patterns in the study period: (top) boxplots for the metrics, (middle) spatial pattern of the metrics for $\mathrm{TB}_{H}$, and (bottom) spatial pattern of the metrics for $\mathrm{TB}_{V}$.

$\mathrm{TB}_{H}$. In terms of unbiased RMSD (ubRMSD) and the bias, $\mathrm{TB}_{V}$ significantly outperforms $\mathrm{TB}_{H}$. Over half of the SMAP grid cells have ubRMSD over $15 \mathrm{~K}$ for $\mathrm{TB}_{H}$, while the ubRMSD is smaller than $15 \mathrm{~K}$ for all cells for $\mathrm{TB}_{V}$. The bias is less than $-10 \mathrm{~K}$ for $\mathrm{TB}_{V}$ for most grid cells, while over half of the grid cells have bias larger than $-10 \mathrm{~K}$ for $\mathrm{TB}_{H}$. Overall, the $\mathrm{OL}$ simulated TB is in better agreement with SMAP observations for vertical polarization than for horizontal polarization, which is a logical consequence of the fact that $\mathrm{TB}_{V}$ is bounded by surface soil temperature and less variable than $\mathrm{TB}_{H}$.

The spatial patterns of the statistical metrics are also shown in Fig. 3 (middle and bottom rows). Generally, the statistical metrics show similar spatial patterns for $\mathrm{TB}_{H}$ and $\mathrm{TB}_{V}$, where the OL simulations agree better with SMAP observations in the southeast part of the study area. The spatial patterns may be caused by the vegetation density. In the study area, a positive gradient of vegetation density is seen from the northwest to the southeast (Lu et al. 2017). With more vegetation, the impact of soil moisture is reduced, which makes TB easier to model. The magnitude and spatial distribution of the statistical metrics for study periods in both years are very similar.

The time series of the differences between OL simulations and SMAP observations for $\mathrm{TB}_{H}$ and $\mathrm{TB}_{V}$ in the 2015 study period is plotted in Fig. 4, and the areal mean SSM from OL simulations and SMAP Level-3 soil moisture product are also plotted for reference. The difference between OL simulated and SMAP observed TB is much smaller for $\mathrm{TB}_{V}$ than for $\mathrm{TB}_{H}$ because $\mathrm{TB}$ is less sensitive to soil moisture in vertical polarization than in horizontal polarization. The temporal evolution of the differences shows similar trends for both $\mathrm{TB}_{H}$ and $\mathrm{TB}_{V}$, closely following the wetting and drying trends of the SSM. 


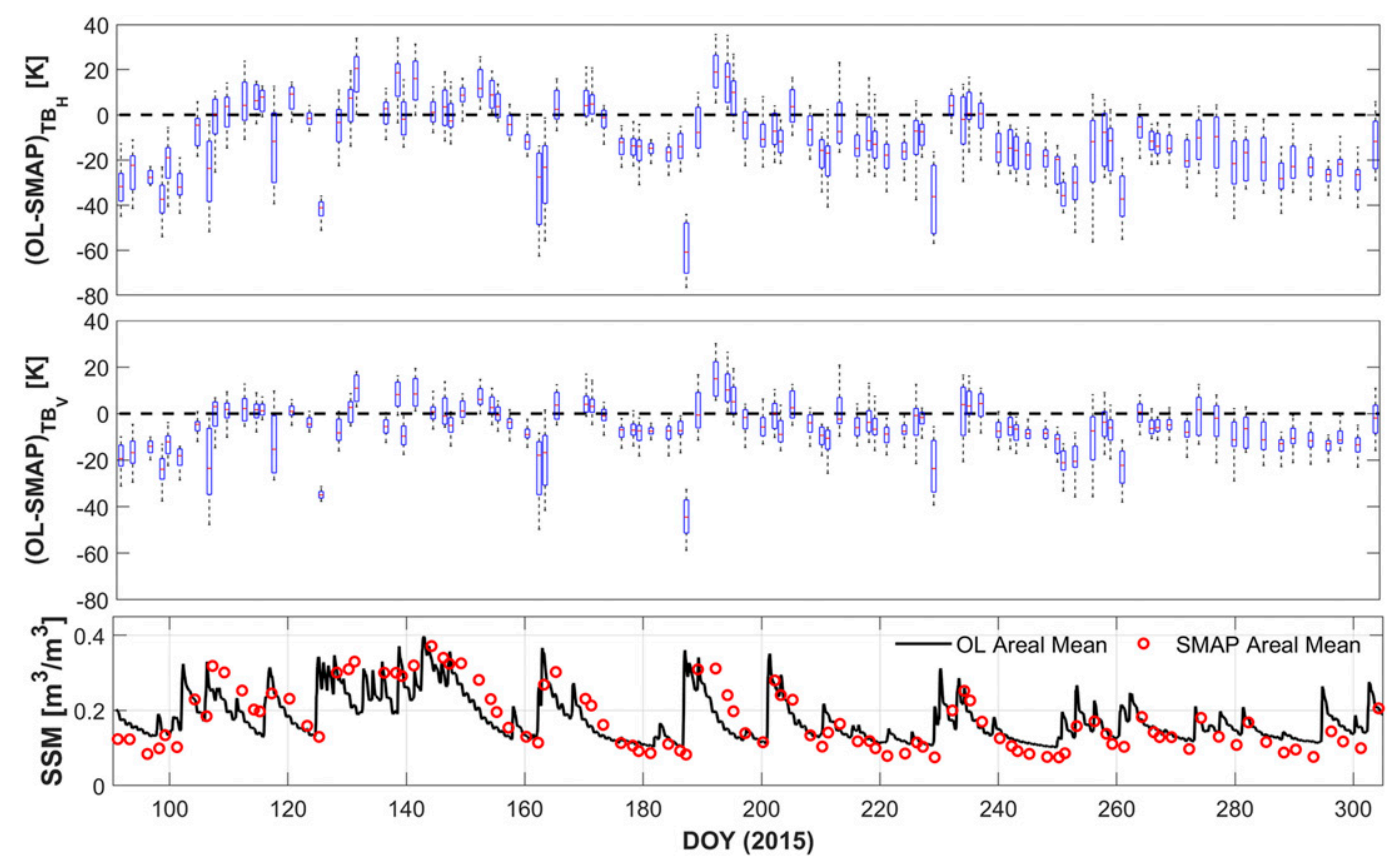

FIG. 4. Boxplot time series of the differences between OL simulations and SMAP observations for $\mathrm{TB}_{H}$ and $\mathrm{TB}_{V}$ in the 16 SMAP grid cells in the 2015 study period. The areal mean soil moisture time series from OL simulations and SMAP is also plotted.

In general, the differences are smaller when the SSM is higher, and get larger when the soil dries down. After rainfall events, the soil moisture profile near the surface becomes very uniform, and the soil emissivity becomes less sensitive to soil moisture (Njoku and Entekhabi 1996). As a result, the uncertainty of TB is very small, despite the relatively shallow sensing depth for L-band radiometer for wet soil (Shellito et al. 2016). Whereas the soil moisture profile gets less uniform with the soil drying down, and the deeper soil moisture influences the soil emissivity for drier soil (Njoku and Entekhabi 1996). Under this condition, a small difference in the sensing depth could lead to a significant difference in TB between SMAP observations and model simulations. In addition, the modeled SSM may dry down faster or slower than the true SSM, exerting different influences under wet or dry conditions. This implies that the difference between OL simulated TB and SMAP observed TB is to some extent related to the soil moisture condition or soil hydraulic properties. Correcting TB bias online as a function of soil moisture therefore could potentially improve TB assimilation schemes. The plots for the 2016 study period show the same patterns (not shown).

\section{b. Soil moisture estimation}

Figure 5 provides the comparison of SSM estimates in the 2015 study period from OL and three joint assimilation cases at the two $0.05^{\circ}$ grid cells that contain soil moisture stations, and the statistical assessments for both years are summarized in Table 3. The assimilation cases include (i) assimilation of GOES LST and SMAP $\mathrm{TB}_{H}$ (hereafter $\mathrm{DA}_{T H}$ ), (ii) assimilation of GOES LST and SMAP $\mathrm{TB}_{V}$ (hereafter $\mathrm{DA}_{T V}$ ), and (iii) assimilation of GOES LST and SMAP Level-3 soil moisture retrievals (hereafter $\mathrm{DA}_{T \theta}$ ) following Lu et al. (2017). In general, the time series of OL closely follows the dynamics of in situ observations at both stations, indicating a good model performance. Assimilating TB observations instead of soil moisture retrievals reduces the estimation bias, particularly in 2016. This may relate to the drier condition in 2016, where surface emissivity is more sensitive to the soil moisture state. At Abrams, $\mathrm{DA}_{T V}$ has the best performance based on all the metrics in both years, while $\mathrm{DA}_{T H}$ and $\mathrm{DA}_{T \theta}$ are mostly comparable. At Stillwater, the estimates are significantly influenced by the erroneous soil hydraulic properties used in the modeling as well as the disagreement in GPM data with in situ precipitation measurements ( $\mathrm{Lu}$ et al. 2017). Despite the influence, $\mathrm{DA}_{T V}$ shows slight improvement over $\mathrm{DA}_{T \theta}$.

The performance of data assimilation in the 2015 study period is also assessed for the second layer $(5-15 \mathrm{~cm})$ and root-zone soil moisture (hereafter RZSM) in Fig. 6. To bridge the difference in the soil column thickness ( $90 \mathrm{~cm}$ for the model and $100 \mathrm{~cm}$ for the measurements), weighted averaging and linear interpolation are conducted respectively for the model simulations and in situ measurements before deriving the RZSM. Similar to the results for SSM, assimilating TB instead of soil moisture 

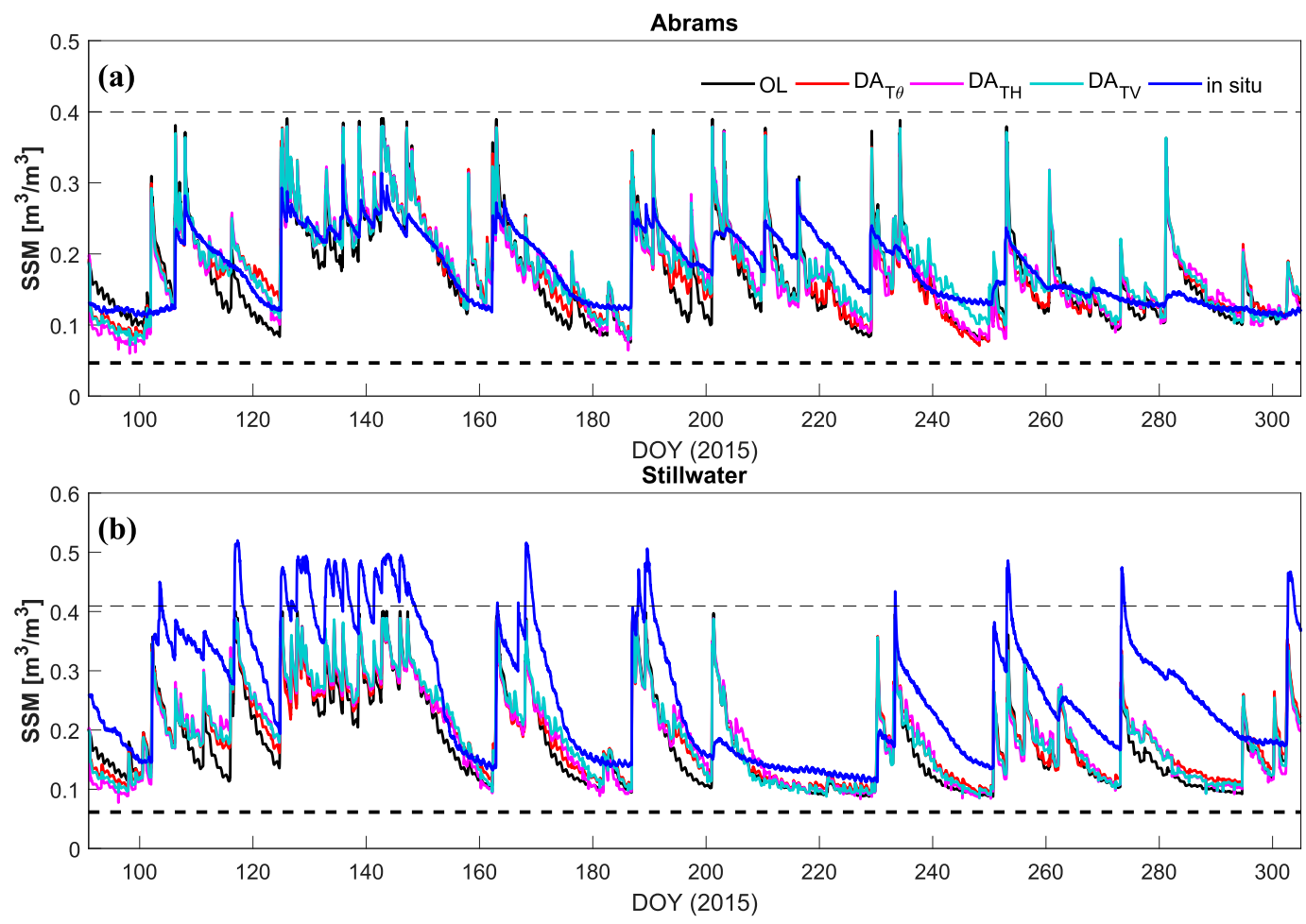

FIG. 5. (a),(b) Time series of OL and assimilation results for SSM, together with in situ measurements at two stations in the 2015 study period. The residual and saturated soil moisture used in the modeling are plotted with the thick and thin dashed lines, respectively. The statistical results are shown in Table 3.

generally yields smaller bias, particularly in 2016 which is drier and in the second layer which is more closely correlated to SSM. Note that $\mathrm{DA}_{T \theta}$ overall produces higher correlations with in situ data than $\mathrm{DA}_{T H}$ and $\mathrm{DA}_{T V}$, which may be attributed to the more direct relationship with soil moisture states. Large bias exists between model simulations and in situ measurements for RZSM in both years, as is also demonstrated in Lu et al. (2019). This is mainly caused by the initialization error resulted from the poor prior knowledge of the soil moisture profile. Since the initial soil moisture is assumed uniform along the column, the soil moisture analysis in the deeper layers will be lower than the truth after SMAP assimilation, because it takes time for the deeper layer soil moisture to reach its climatological values ( $\mathrm{Lu}$ et al. 2019). Furthermore, in situ measurements suggest that the soil from the deepest layer is almost always saturated, which also contributes to the large bias.

Overall, the difference in soil moisture estimates from assimilating SMAP soil moisture retrievals or TB observations is not pronounced. This may be mainly explained by the consistent $T_{\text {eff }}$ data as well as RTM parameters used in the SMAP retrieval system and the model simulations in this study. The simulated $T_{\text {eff }}$ in this study is generally lower than that used for SMAP soil moisture retrieval, with a mean gap of $-3 \mathrm{~K}$ for 2015 and $-10 \mathrm{~K}$ for 2016 for both $\mathrm{DA}_{T H}$ and $\mathrm{DA}_{T V}$. The gap is small compared to the magnitude of $T_{\text {eff }}(280-310 \mathrm{~K})$, and its influence on TB is mitigated by the land surface emissivity $(<1)$. In addition, the RTM parameters used are consistent with each other, which also contributes to the small difference in TB estimates. More importantly, since the gap is consistently negative, the mean bias correction adopted for TB could effectively reduce the gap. It should be noted that as a result of the relatively short record of the SMAP data, only short-term bias can be corrected for, which reduces the information contained in the SMAP observations. LST states after updates are not evaluated due to lack of in situ data, but are expected to have smaller bias and phase error thanks to the relatively frequent (hourly) information input from GOES (Lu et al. 2017).

\section{c. Flux estimation}

The 30-min $H$ and LE estimates in the whole study period are assessed against in situ measurements at the four flux stations in Fig. 7, and the statistical metrics are also summarized in Table 5. The OL estimates feature relatively large bias, since the soil wetness and thermal states are not updated, which has an impact on net radiation estimation. All three assimilation strategies show improvement over OL simulations, particularly for LE 
TABLE 3. Statistical assessment of soil moisture estimates at different depths against in situ measurements for OL, $\mathrm{DA}_{T \theta}$, $\mathrm{DA}_{T H}$, and $\mathrm{DA}_{T V}$ (unit of ubRMSD, RMSD, and bias is $\mathrm{m}^{3} \mathrm{~m}^{-3}$ ). The best performance in each category is shown in bold.

\begin{tabular}{|c|c|c|c|c|c|c|c|c|c|}
\hline & & \multicolumn{4}{|c|}{ Abrams } & \multicolumn{4}{|c|}{ Stillwater } \\
\hline & & ubRMSD & RMSD & Bias & $R$ & ubRMSD & RMSD & Bias & $R$ \\
\hline & & \multicolumn{8}{|c|}{2015} \\
\hline \multirow[t]{4}{*}{ SSM } & $\mathrm{OL}$ & 0.043 & 0.044 & -0.009 & 0.73 & 0.064 & 0.107 & -0.085 & 0.82 \\
\hline & $\mathrm{DA}_{T \theta}$ & 0.040 & 0.041 & -0.004 & 0.75 & 0.063 & 0.097 & -0.074 & 0.84 \\
\hline & $\mathrm{DA}_{T H}$ & 0.039 & 0.039 & -0.002 & 0.77 & 0.063 & 0.097 & -0.074 & 0.83 \\
\hline & $\mathrm{DA}_{T V}$ & 0.037 & 0.037 & 0.002 & 0.78 & 0.061 & 0.095 & -0.073 & 0.84 \\
\hline \multirow[t]{4}{*}{ Second layer } & $\mathrm{OL}$ & 0.044 & 0.046 & -0.014 & 0.65 & 0.054 & 0.134 & -0.122 & 0.80 \\
\hline & $\mathrm{DA}_{T \theta}$ & 0.038 & 0.041 & -0.014 & 0.73 & 0.054 & 0.127 & -0.115 & 0.81 \\
\hline & $\mathrm{DA}_{T H}$ & 0.039 & 0.041 & -0.013 & 0.73 & 0.055 & 0.127 & -0.115 & 0.79 \\
\hline & $\mathrm{DA}_{T V}$ & 0.038 & 0.039 & -0.009 & 0.72 & 0.053 & 0.125 & -0.113 & 0.81 \\
\hline \multirow[t]{5}{*}{ RZSM } & $\mathrm{OL}$ & 0.030 & 0.132 & -0.128 & 0.63 & 0.040 & 0.206 & -0.202 & 0.60 \\
\hline & $\mathrm{DA}_{T \theta}$ & 0.036 & 0.133 & -0.128 & 0.59 & 0.040 & 0.193 & -0.188 & 0.62 \\
\hline & $\mathrm{DA}_{T H}$ & 0.037 & 0.134 & -0.128 & 0.56 & 0.042 & 0.191 & -0.187 & 0.61 \\
\hline & $\mathrm{DA}_{T V}$ & 0.031 & 0.129 & -0.125 & 0.62 & 0.040 & 0.190 & -0.186 & 0.64 \\
\hline & & \multicolumn{8}{|c|}{2016} \\
\hline \multirow[t]{4}{*}{ SSM } & $\mathrm{OL}$ & 0.042 & 0.048 & -0.023 & 0.66 & 0.063 & 0.093 & -0.068 & 0.68 \\
\hline & $\mathrm{DA}_{T \theta}$ & 0.042 & 0.045 & -0.016 & 0.65 & 0.056 & 0.084 & -0.063 & 0.76 \\
\hline & $\mathrm{DA}_{T H}$ & 0.043 & 0.046 & -0.017 & 0.64 & 0.060 & 0.077 & -0.049 & 0.72 \\
\hline & $\mathrm{DA}_{T V}$ & 0.040 & 0.041 & -0.011 & 0.68 & 0.061 & 0.080 & -0.051 & 0.70 \\
\hline \multirow[t]{4}{*}{ Second layer } & OL & 0.034 & 0.035 & 0.007 & 0.62 & 0.054 & 0.123 & -0.110 & 0.67 \\
\hline & $\mathrm{DA}_{T \theta}$ & 0.034 & 0.035 & 0.009 & 0.65 & 0.049 & 0.117 & -0.106 & 0.76 \\
\hline & $\mathrm{DA}_{T H}$ & 0.038 & 0.038 & 0.006 & 0.57 & 0.050 & 0.104 & -0.091 & 0.72 \\
\hline & $\mathrm{DA}_{T V}$ & 0.034 & 0.037 & 0.014 & 0.64 & 0.053 & 0.108 & -0.094 & 0.69 \\
\hline \multirow[t]{4}{*}{ RZSM } & $\mathrm{OL}$ & 0.033 & 0.131 & -0.127 & 0.31 & 0.041 & 0.203 & -0.199 & 0.71 \\
\hline & $\mathrm{DA}_{T \theta}$ & 0.031 & 0.120 & -0.116 & 0.50 & 0.039 & 0.188 & -0.184 & 0.79 \\
\hline & $\mathrm{DA}_{T H}$ & 0.035 & 0.129 & -0.124 & 0.31 & 0.053 & 0.173 & -0.165 & 0.30 \\
\hline & $\mathrm{DA}_{T V}$ & 0.033 & 0.115 & 0.110 & 0.37 & 0.052 & 0.176 & -0.168 & 0.28 \\
\hline
\end{tabular}

estimates, which relates to a better characterization of soil moisture dynamics. Flux estimates from the three assimilation strategies are in general very similar, since the differences in soil moisture estimates are not pronounced. As soil moisture influences surface energy fluxes by constraining energy partitioning through an arctangentform relationship, the influence is expected to be large for dry soil and small for wet soil. As demonstrated in Figs. 5 and 6, the larger soil moisture differences are mostly seen when the soil wetness is medium or high, where the EF estimates approach the plateau. While the difference when the soil is dry is limited by the residual soil moisture threshold. As a result, the small differences in soil moisture do not lead to large differences in EF estimates, which is further reduced by the \pm 0.2 uncertainty range given to the reference $\mathrm{EF}$. $\mathrm{DA}_{T V}$ slightly outperforms $\mathrm{DA}_{T H}$, indicated by the smaller RMSD and higher correlation, but the difference is not significant, and even less visible for the 2016 study period. The scatterplots of 30-min flux estimates are also provided in the online supplemental material. The $H$ and LE estimates at daytime (0900-1600 LT) scale yield similar results (not shown).

Figure 8 shows the KGE between 30-min flux estimates from each pair of assimilation strategies in the whole study period to check the consistency between strategies. Overall, the three assimilation strategies yield very similar flux estimates across the study area for both $H$ and LE. This is expected since the soil moisture estimates from assimilating different datasets are very consistent and in line with each other. It is demonstrated that the KGE between $\mathrm{DA}_{T H}$ or $\mathrm{DA}_{T V}$ and $\mathrm{DA}_{T \theta}$ is generally above 0.8 for $30-\mathrm{min} H$, while the KGE for 30-min LE is above 0.9 for most of the area, indicating a very good agreement between different assimilation strategies. The KGE for $H$ is lower than that for LE since $H$ is more susceptible to small variations in environmental factors (e.g., wind speed). The KGE for 2016 is generally higher than for 2015 for both $H$ and LE estimates since the LST time series contains more information on surface energy partitioning for drier soil. As a result, the surface energy fluxes are more tightly constrained by LST dynamics, which essentially reduces the estimation uncertainty. Similar results are obtained for results at daytime scale (not shown).

\section{d. Comparison with univariate assimilation cases}

To evaluate the marginal benefit of assimilating data from either thermal (LST) or passive microwave (soil 

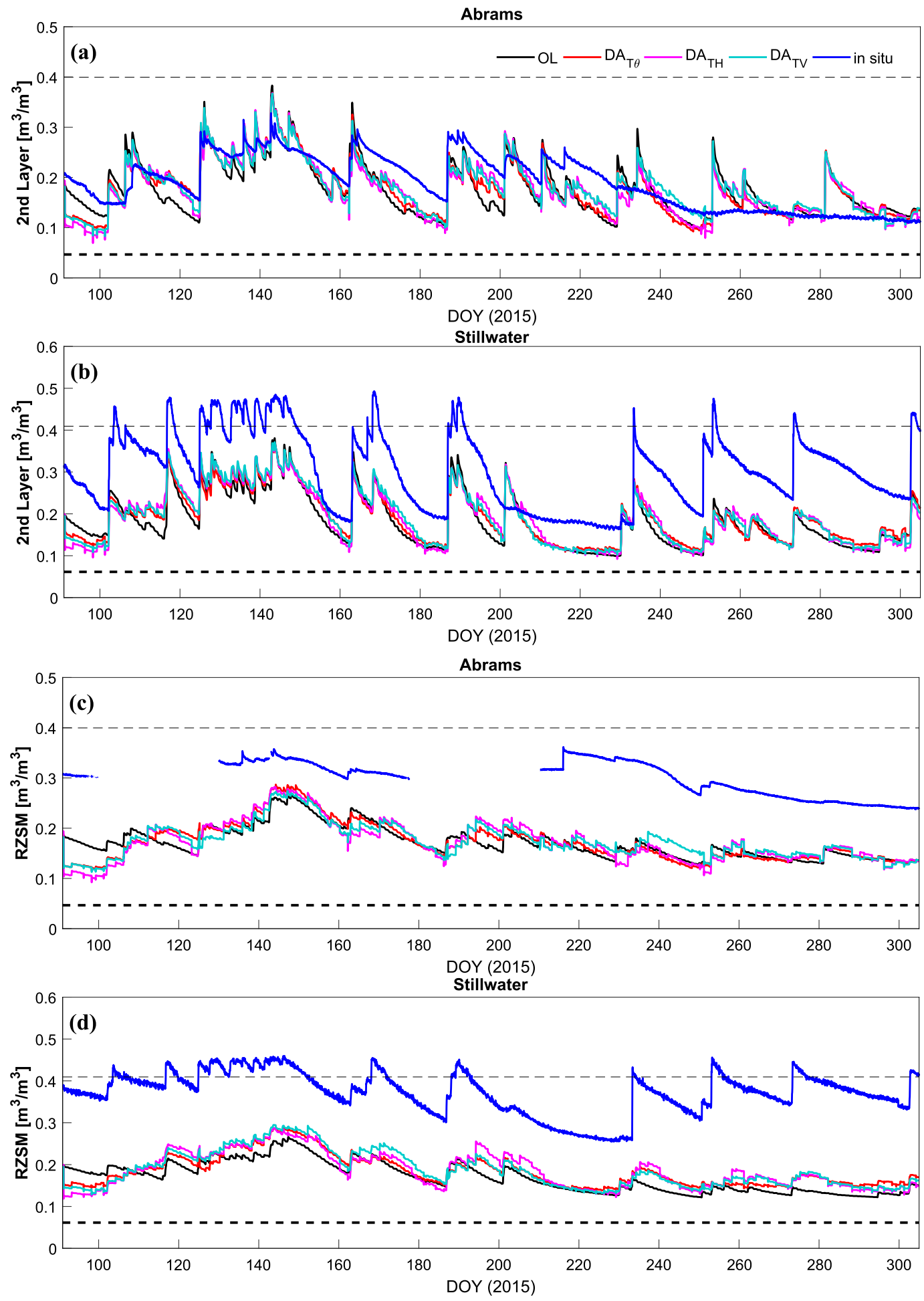

FIG. 6. As in Fig. 5, but for the (a),(b) second layer $(5-15 \mathrm{~cm})$ and (c),(d) root-zone soil moisture.

moisture or TB) remote sensing, the soil moisture and flux estimates are further compared to those from four univariate assimilation cases: (i) LST-only assimilation $\left(\mathrm{DA}_{T}\right)$, (ii) soil moisture-only assimilation $\left(\mathrm{DA}_{\theta}\right)$, (iii) $\mathrm{TB}_{H^{-}}$-only assimilation $\left(\mathrm{DA}_{H}\right.$ ), and (iv) $\mathrm{TB}_{V}$-only assimilation $\left(\mathrm{DA}_{V}\right)$. The soil moisture estimates at different depths from univariate assimilation cases are shown in Table 4. The univariate assimilation 


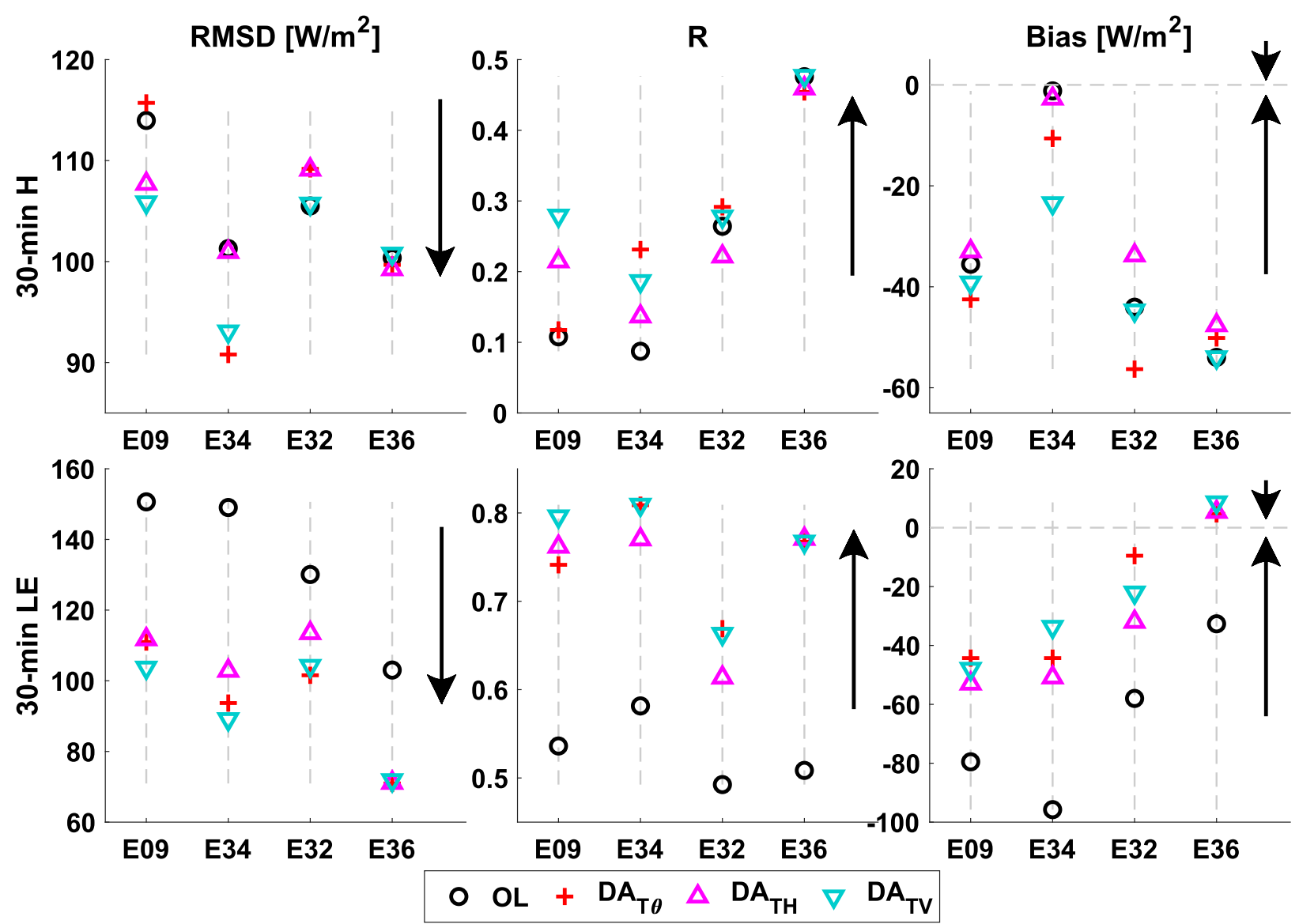

FIG. 7. Assessment of 30-min $H$ and LE estimates from OL, DA ${ }_{T \theta}, \mathrm{DA}_{T H}$, and $\mathrm{DA}_{T V}$ at four flux stations in the study period. The black arrows indicate the directions of better estimates in each plot.

cases generally lead to improved soil moisture estimates compared to the OL simulations, shown by either the reduced ubRMSD or the higher correlation with in situ measurements. $\mathrm{DA}_{T}$ tends to yield larger estimation bias, which may be caused by the indirect relationship between temperature and soil moisture. $\mathrm{DA}_{\theta}, \mathrm{DA}_{H}$, and $\mathrm{DA}_{V}$ produce very similar soil moisture estimates, which is consistent with the joint assimilation cases. Comparing the univariate assimilation cases with the multivariate data assimilation cases (summarized in Table 3), $\mathrm{DA}_{T \theta}, \mathrm{DA}_{T H}$, and $\mathrm{DA}_{T V}$ yield soil moisture estimates with smaller ubRMSD than the corresponding univariate assimilation cases $\left(\mathrm{DA}_{\theta}, \mathrm{DA}_{H}\right.$, and $\left.\mathrm{DA}_{V}\right)$, and the reduction in the bias is also evident and introduced by the parameter updating. When LST data are jointly assimilated, the surface energy partitioning is more tightly constrained, which is expected to benefit soil moisture estimates. Overall, the multivariate assimilation cases yield better soil moisture estimates than the univariate assimilation cases.

The statistical assessment of 30-min flux estimates from the univariate assimilation cases is summarized in Table 5. Flux estimates from $\mathrm{DA}_{\theta}, \mathrm{DA}_{H}$, and $\mathrm{DA}_{V}$ are very similar as a result of the comparable soil moisture estimates. $\mathrm{DA}_{T}$ yields a small $H$ estimation bias thanks to the LST and key parameter updates. Likewise, when only soil moisture information is assimilated $\left(\mathrm{DA}_{\theta}, \mathrm{DA}_{H}\right.$, and $\left.\mathrm{DA}_{V}\right)$, the flux estimation bias may be large since only soil moisture states can be updated (Lu et al. 2017). The multivariate assimilation cases yield flux estimates with smaller RMSD and higher correlation with in situ measurements than the univariate assimilation cases, particularly in LE estimates. It is worth noting that flux estimates from $\mathrm{DA}_{T}$ can be worse than those from $\mathrm{OL}$ (e.g., $H$ estimates at E34 station). This may relate to a poor characterization of soil moisture dynamics (Lu et al. 2017), which highlights the importance of assimilating soil moisture information. Overall, joint assimilation of LST and soil moisture information outperforms univariate assimilation strategies in flux estimation.

\section{Conclusions}

In this study, SMAP brightness temperature (TB) data or soil moisture retrievals are assimilated into a 

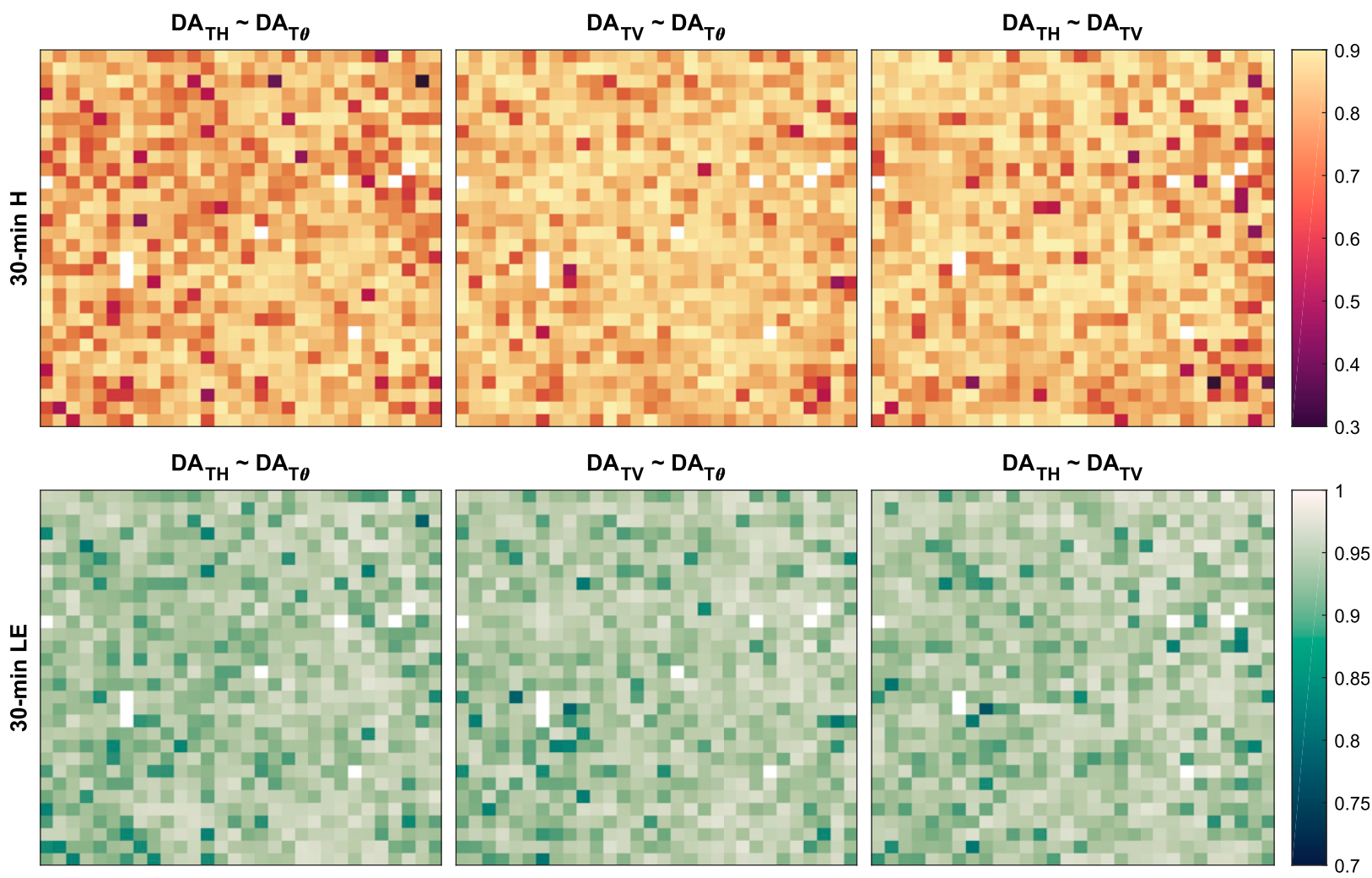

FIG. 8. Intercomparison of the KGEs of 30-min $H$ and LE estimates from $\mathrm{DA}_{T \theta}, \mathrm{DA}_{T H}$, and $\mathrm{DA}_{T V}$ in the study period.

coupled water and heat transfer model with GOES land surface temperature (LST) retrievals to improve soil moisture and surface turbulent heat flux estimates. The methodology aims to estimate two key parameters: a neutral bulk heat transfer coefficient $C_{H N}$ and a daytime-constant evaporative fraction (EF). This study is based on a previous research but is augmented by the coupling with a radiative transfer model (RTM) to enable direct TB assimilation. The methodology is tested in an area in the U.S. Southern Great Plains for two growing seasons (April-October) in 2015 and 2016. Either TB at horizontal $\left(\mathrm{TB}_{H}\right)$ or vertical $\left(\mathrm{TB}_{V}\right)$ polarization is assimilated along with GOES LST data, and the estimates are compared to in situ observations and an experiment that assimilates SMAP Level-3 soil moisture retrievals instead following $\mathrm{Lu}$ et al. (2017).

The agreement between the modeled and SMAP observed TB is higher for $\mathrm{TB}_{V}$ than for $\mathrm{TB}_{H}$. Analysis of the TB time series of the differences between OL simulations and SMAP observations suggests that the difference between simulation and observation is to some extent related to the soil moisture condition.

All three assimilation strategies improve surface soil moisture estimates compared to the OL simulation.
Improvement is also seen in deeper layers, though to a lesser degree than at the surface. Overall, the soil moisture estimates from different assimilation strategies are in line with each other, while $\mathrm{DA}_{T H}$ and $\mathrm{DA}_{T V}$ tend to yield smaller estimation bias. Here the soil moisture profile is initialized randomly and assumed uniform in order to assess the utilities of assimilating passive microwave information without ground measurements a priori. The soil moisture estimates are expected to benefit from initialization using in situ data and a long spinup period.

Assimilation also leads to improved $H$ and LE estimates compared to $\mathrm{OL}$ estimates. $\mathrm{DA}_{T \theta}, \mathrm{DA}_{T H}$, and $\mathrm{DA}_{T V}$ yield very similar flux estimates at both daytime and 30-min scale. Since the difference in soil moisture estimates from different experiments is not pronounced, the influence on EF estimates is limited, which is further reduced by the uncertainty range given to the reference EF estimates. A further comparison with univariate assimilation cases suggests that joint assimilation of LST and soil moisture information has the best performance in soil moisture and flux estimation.

It is worth noting that the performance of TB assimilation depends to a large extent on the bias correction as well as the characterization of model and observation 
TABLE 4. Statistical assessment of soil moisture estimates at different depths against in situ measurements for univariate assimilation cases (unit of ubRMSD, RMSD, and bias is $\mathrm{m}^{3} \mathrm{~m}^{-3}$ ).

\begin{tabular}{|c|c|c|c|c|c|c|c|c|c|}
\hline & & \multicolumn{4}{|c|}{ Abrams } & \multicolumn{4}{|c|}{ Stillwater } \\
\hline & & ubRMSD & RMSD & Bias & $R$ & ubRMSD & RMSD & Bias & $R$ \\
\hline & & \multicolumn{8}{|c|}{2015} \\
\hline \multirow[t]{4}{*}{ SSM } & $\mathrm{DA}_{T}$ & 0.047 & 0.048 & -0.010 & 0.69 & 0.060 & 0.103 & -0.084 & 0.84 \\
\hline & $\mathrm{DA}_{\theta}$ & 0.040 & 0.041 & -0.008 & 0.76 & 0.065 & 0.100 & -0.077 & 0.83 \\
\hline & $\mathrm{DA}_{H}$ & 0.041 & 0.042 & -0.010 & 0.76 & 0.064 & 0.101 & -0.078 & 0.83 \\
\hline & $\mathrm{DA}_{V}$ & 0.040 & 0.040 & -0.002 & 0.75 & 0.063 & 0.101 & -0.078 & 0.83 \\
\hline \multirow[t]{4}{*}{ Second layer } & $\mathrm{DA}_{T}$ & 0.047 & 0.050 & -0.018 & 0.63 & 0.051 & 0.135 & -0.125 & 0.83 \\
\hline & $\mathrm{DA}_{\theta}$ & 0.038 & 0.041 & -0.016 & 0.74 & 0.055 & 0.128 & -0.116 & 0.81 \\
\hline & $\mathrm{DA}_{H}$ & 0.044 & 0.047 & -0.019 & 0.66 & 0.054 & 0.129 & -0.117 & 0.81 \\
\hline & $\mathrm{DA}_{V}$ & 0.044 & 0.045 & -0.010 & 0.65 & 0.053 & 0.129 & -0.117 & 0.82 \\
\hline \multirow[t]{5}{*}{ RZSM } & $\mathrm{DA}_{T}$ & 0.035 & 0.145 & -0.140 & 0.61 & 0.041 & 0.212 & -0.208 & 0.65 \\
\hline & $\mathrm{DA}_{\theta}$ & 0.038 & 0.134 & -0.128 & 0.58 & 0.040 & 0.193 & -0.189 & 0.61 \\
\hline & $\mathrm{DA}_{H}$ & 0.037 & 0.136 & -0.131 & 0.55 & 0.040 & 0.196 & -0.192 & 0.61 \\
\hline & $\mathrm{DA}_{V}$ & 0.036 & 0.124 & -0.119 & 0.60 & 0.038 & 0.192 & -0.188 & 0.65 \\
\hline & & \multicolumn{8}{|c|}{2016} \\
\hline \multirow[t]{4}{*}{ SSM } & $\mathrm{DA}_{T}$ & 0.046 & 0.055 & -0.030 & 0.66 & 0.056 & 0.098 & -0.080 & 0.76 \\
\hline & $\mathrm{DA}_{\theta}$ & 0.043 & 0.050 & -0.025 & 0.65 & 0.058 & 0.087 & -0.065 & 0.74 \\
\hline & $\mathrm{DA}_{H}$ & 0.043 & 0.048 & -0.022 & 0.66 & 0.062 & 0.088 & -0.063 & 0.70 \\
\hline & $\mathrm{DA}_{V}$ & 0.041 & 0.046 & -0.020 & 0.67 & 0.061 & 0.087 & -0.062 & 0.70 \\
\hline \multirow[t]{4}{*}{ Second layer } & $\mathrm{DA}_{T}$ & 0.037 & 0.037 & -0.005 & 0.68 & 0.050 & 0.133 & -0.123 & 0.73 \\
\hline & $\mathrm{DA}_{\theta}$ & 0.034 & 0.034 & 0.002 & 0.66 & 0.050 & 0.118 & -0.107 & 0.75 \\
\hline & $\mathrm{DA}_{H}$ & 0.037 & 0.037 & 0.004 & 0.63 & 0.052 & 0.116 & -0.104 & 0.70 \\
\hline & $\mathrm{DA}_{V}$ & 0.035 & 0.035 & 0.006 & 0.63 & 0.052 & 0.116 & -0.103 & 0.70 \\
\hline \multirow[t]{4}{*}{ RZSM } & $\mathrm{DA}_{T}$ & 0.028 & 0.146 & -0.143 & 0.60 & 0.031 & 0.216 & -0.214 & 0.82 \\
\hline & $\mathrm{DA}_{\theta}$ & 0.030 & 0.128 & -0.124 & 0.56 & 0.038 & 0.188 & -0.184 & 0.84 \\
\hline & $\mathrm{DA}_{H}$ & 0.031 & 0.127 & -0.123 & 0.50 & 0.045 & 0.188 & -0.183 & 0.54 \\
\hline & $\mathrm{DA}_{V}$ & 0.035 & 0.126 & -0.121 & 0.25 & 0.044 & 0.188 & -0.182 & 0.57 \\
\hline
\end{tabular}

errors. In this study, a RTM similar to the one used in the SMAP Level-2/3 soil moisture retrieval is used for TB forward simulation. Using another RTM with a different parameterization may lead to slightly different results. Likewise, the choice to have the LST smoother correct for the bias by updating parameters may affect the results in a different way than if bias was corrected for a priori as in Reichle et al. (2010). Regional optimization of parameters or dynamic online bias correction may further improve flux estimates.

TABLE 5. Statistical assessment of 30-min $H$ and LE estimates from OL and different assimilation cases at four flux stations in the study period.

\begin{tabular}{|c|c|c|c|c|c|c|c|c|c|c|c|c|c|}
\hline & & \multicolumn{4}{|c|}{$\operatorname{RMSD}\left(\mathrm{W} \mathrm{m}^{-2}\right)$} & \multicolumn{4}{|c|}{$R$} & \multicolumn{4}{|c|}{$\operatorname{Bias}\left(\mathrm{W} \mathrm{m}^{-2}\right)$} \\
\hline & & E09 & E34 & E32 & E36 & E09 & E34 & E32 & E36 & E09 & E34 & E32 & E36 \\
\hline \multirow[t]{8}{*}{$30-\min H$} & $\mathrm{OL}$ & 114.0 & 101.3 & 105.5 & 100.4 & 0.11 & 0.09 & 0.26 & 0.48 & -35.5 & -1.2 & -44.0 & -54.0 \\
\hline & $\mathrm{DA}_{T \theta}$ & 115.7 & 90.8 & 109.2 & 99.7 & 0.12 & 0.23 & 0.29 & 0.45 & -42.5 & -10.6 & -56.3 & -50.1 \\
\hline & $\mathrm{DA}_{T H}$ & 107.7 & 100.9 & 109.1 & 99.2 & 0.21 & 0.14 & 0.22 & 0.46 & -33.0 & -2.7 & -33.8 & -47.6 \\
\hline & $\mathrm{DA}_{T V}$ & 105.9 & 93.1 & 105.7 & 100.8 & 0.28 & 0.19 & 0.28 & 0.48 & -39.2 & -23.4 & -44.7 & -54.0 \\
\hline & $\mathrm{DA}_{T}$ & 113.9 & 131.8 & 108.1 & 99.7 & 0.15 & -0.02 & 0.20 & 0.45 & -22.9 & 22.8 & -18.3 & -27.5 \\
\hline & $\mathrm{DA}_{\theta}$ & 110.8 & 90.8 & 106.6 & 109.7 & 0.26 & 0.16 & 0.37 & 0.47 & -55.2 & -22.1 & -59.6 & -71.4 \\
\hline & $\mathrm{DA}_{H}$ & 112.6 & 93.3 & 104.6 & 102.8 & 0.23 & 0.14 & 0.34 & 0.51 & -53.6 & -18.9 & -51.7 & -63.1 \\
\hline & $\mathrm{DA}_{V}$ & 112.3 & 92.2 & 106.1 & 108.5 & 0.22 & 0.14 & 0.34 & 0.50 & -52.8 & -18.7 & -55.9 & -71.7 \\
\hline \multirow[t]{8}{*}{ 30-min LE } & $\mathrm{OL}$ & 150.6 & 149.0 & 130.1 & 103.0 & 0.54 & 0.58 & 0.49 & 0.51 & -79.5 & -95.8 & -58.0 & -32.6 \\
\hline & $\mathrm{DA}_{T \theta}$ & 111.0 & 93.7 & 101.6 & 70.9 & 0.74 & 0.81 & 0.67 & 0.77 & -44.3 & -44.3 & -9.5 & 4.7 \\
\hline & $\mathrm{DA}_{T H}$ & 111.7 & 102.8 & 113.5 & 71.1 & 0.76 & 0.77 & 0.61 & 0.77 & -53.0 & -50.9 & -32.0 & 5.4 \\
\hline & $\mathrm{DA}_{T V}$ & 103.7 & 89.1 & 104.2 & 71.9 & 0.80 & 0.81 & 0.66 & 0.77 & -47.9 & -33.7 & -22.0 & 8.6 \\
\hline & $\mathrm{DA}_{T}$ & 120.6 & 138.3 & 117.7 & 85.9 & 0.71 & 0.61 & 0.60 & 0.70 & -56.8 & -77.5 & -44.3 & -20.8 \\
\hline & $\mathrm{DA}_{\theta}$ & 124.6 & 115.6 & 109.7 & 76.9 & 0.70 & 0.75 & 0.63 & 0.70 & -58.5 & -68.1 & -40.3 & -11.4 \\
\hline & $\mathrm{DA}_{H}$ & 130.0 & 123.4 & 120.6 & 85.1 & 0.64 & 0.71 & 0.56 & 0.65 & -58.5 & -74.4 & -50.2 & -19.0 \\
\hline & $\mathrm{DA}_{V}$ & 127.8 & 121.1 & 116.1 & 83.9 & 0.67 & 0.73 & 0.58 & 0.65 & -59.9 & -72.6 & -43.0 & -12.4 \\
\hline
\end{tabular}


Here the methodology is applied in an area mainly covered by grassland and cropland with a temperate climate. The key to improving surface heat flux estimates through joint LST and TB assimilation lies in the constraint of soil wetness conditions on surface energy partitioning and the capability of LST time series to characterize the surface energy dynamics during the daytime. The former is expected to be valid for a large range of land cover types and vegetation conditions, while the latter is impacted by high soil wetness condition as well as the cloud cover contamination. For very wet areas, the magnitude of daytime LST variation is decreased and the flux partitioning is more energy-limited, which would weaken the LST constraint on energy partitioning. For areas with frequent cloud cover, the availability of remote sensing LST observations is reduced, which would lead to larger uncertainties in the flux estimates. Some studies have suggested that GOES LST time series contains sufficient information on surface energy partitioning over forested areas (Xu et al. 2018), while others have successfully constrained surface energy partitioning with soil wetness information over woody savannah (Farhadi et al. 2014). Further in-depth research is needed to evaluate the performance of the methodology for areas of other land cover types and climatic conditions. The influence of canopy structure on solar radiation partitioning and of different root-zone depth on soil moisture simulation should also be addressed. In addition, introducing a vegetation constraint on energy fluxes may further improve flux estimates (Lu et al. 2019), particularly for areas with very dense vegetation cover. Using a layered heat transfer model (e.g., heat diffusion model) may also reduce the impact of uncertainties in the lower boundary condition on land surface temperature simulation and the phase error of ground heat flux estimates (Bateni et al. 2013).

Acknowledgments. The first author was financially supported for his $\mathrm{Ph}$.D. research by the China Scholarship Council (CSC) (Ref. 201306040112). The datasets used in this study can be obtained from the sources provided in section 2a. Some color maps from Thyng et al. (2016) were used.

\section{REFERENCES}

Abdolghafoorian, A., L. Farhadi, S. M. Bateni, S. Margulis, and T. Xu, 2017: Characterizing the effect of vegetation dynamics on the bulk heat transfer coefficient to improve variational estimation of surface turbulent fluxes. J. Hydrometeor., 18, 321-333, https://doi.org/10.1175/JHM-D-16-0097.1.

Allen, R. G., M. Tasumi, and R. Trezza, 2007: Satellite-based energy balance for mapping evapotranspiration with internalized calibration (METRIC)-model. J. Irrig. Drain. Eng., 133, 380-394, https://doi.org/10.1061/(ASCE)0733-9437(2007) 133:4(380).
Anderson, M., and Coauthors, 2011: Mapping daily evapotranspiration at field to continental scales using geostationary and polar orbiting satellite imagery. Hydrol. Earth Syst. Sci., 15, 223-239, https://doi.org/10.5194/hess-15-223-2011.

Baldocchi, D., and Coauthors, 2001: FLUXNET: A new tool to study the temporal and spatial variability of ecosystem-scale carbon dioxide, water vapor, and energy flux densities. Bull. Amer. Meteor. Soc., 82, 2415-2434, https://doi.org/10.1175/ 1520-0477(2001)082<2415:FANTTS >2.3.CO;2.

Bastiaanssen, W., M. Menenti, R. Feddes, and A. Holtslag, 1998a: A remote sensing surface energy balance algorithm for land (SEBAL). 1. Formulation. J. Hydrol., 212-213, 198-212, https:// doi.org/10.1016/S0022-1694(98)00253-4.

_ , H. Pelgrum, J. Wang, Y. Ma, J. Moreno, G. Roerink, and T. Van der Wal, 1998b: A remote sensing surface energy balance algorithm for land (SEBAL).: Part 2: Validation. J. Hydrol., 212-213, 213-229, https://doi.org/10.1016/S0022-1694(98)00254-6.

Bateni, S., and D. Entekhabi, 2012: Surface heat flux estimation with the ensemble Kalman smoother: Joint estimation of state and parameters. Water Resour. Res., 48, W08521, https:// doi.org/10.1029/2011WR011542.

_ dual-source data assimilation approach adjoined to the heat diffusion equation. J. Geophys. Res., 117, D17118, https://doi.org/ 10.1029/2012JD017618.

_ D. Entekhabi, and D.-S. Jeng, 2013: Variational assimilation of land surface temperature and the estimation of surface energy balance components. J. Hydrol., 481, 143-156, https:// doi.org/10.1016/j.jhydrol.2012.12.039.

Bell, J. E., and Coauthors, 2013: US Climate Reference Network soil moisture and temperature observations. J. Hydrometeor., 14, 977-988, https://doi.org/10.1175/JHM-D-12-0146.1.

Cai, X., and Coauthors, 2017: Validation of SMAP soil moisture for the SMAPVEX15 field campaign using a hyper-resolution model. Water Resour. Res., 53, 3013-3028, https://doi.org/ 10.1002/2016WR019967.

Caparrini, F., F. Castelli, and D. Entekhabi, 2003: Mapping of landatmosphere heat fluxes and surface parameters with remote sensing data. Bound.-Layer Meteor., 107, 605-633, https:// doi.org/10.1023/A:1022821718791.

,-- , and,$- 2004 \mathrm{a}$ : Estimation of surface turbulent fluxes through assimilation of radiometric surface temperature sequences. J. Hydrometeor., 5, 145-159, https://doi.org/10.1175/ 1525-7541(2004)005<0145:EOSTFT>2.0.CO;2.

,$- \ldots$, and,$- 2004 \mathrm{~b}$ : Variational estimation of soil and vegetation turbulent transfer and heat flux parameters from sequences of multisensor imagery. Water Resour. Res., 40, W12515, https://doi.org/10.1029/2004WR003358.

Carrera, M. L., B. Bilodeau, S. Bélair, M. Abrahamowicz, A. Russell, and X. Wang, 2019: Assimilation of passive L-band microwave brightness temperatures in the Canadian Land Data Assimilation System: Impacts on short-range warm season numerical weather prediction. J. Hydrometeor., 20, 1053 1079, https://doi.org/10.1175/JHM-D-18-0133.1.

Chirouze, J., and Coauthors, 2014: Intercomparison of four remotesensing-based energy balance methods to retrieve surface evapotranspiration and water stress of irrigated fields in semi-arid climate. Hydrol. Earth Syst. Sci., 18, 1165-1188, https://doi.org/10.5194/hess-18-1165-2014.

Choudhury, B., T. J. Schmugge, A. Chang, and R. Newton, 1979: Effect of surface roughness on the microwave emission from soils. J. Geophys. Res., 84, 5699-5706, https://doi.org/10.1029/ JC084iC09p05699. 
— fective soil temperature for microwave emission. J. Geophys. Res., 87, 1301-1304, https://doi.org/10.1029/JC087iC02p01301.

Colliander, A., and Coauthors, 2017: Validation of SMAP surface soil moisture products with core validation sites. Remote Sens. Environ., 191, 215-231, https://doi.org/10.1016/j.rse.2017.01.021.

Crago, R. D., 1996: Conservation and variability of the evaporative fraction during the daytime. J. Hydrol., 180, 173-194, https:// doi.org/10.1016/0022-1694(95)02903-6.

_ preservation of the evaporative fraction and the Bowen ratio. J. Hydrol., 178, 241-255, https://doi.org/10.1016/0022-1694(95) 02803-X.

Crow, W. T., R. D. Koster, R. H. Reichle, and H. O. Sharif, 2005: Relevance of time-varying and time-invariant retrieval error sources on the utility of spaceborne soil moisture products. Geophys. Res. Lett., 32, L24405, https://doi.org/10.1029/ 2005 GL024889.

Das, N. N., 2013: SMAP ancillary data report: Soil attributes. SMAP Science Doc. 044, JPL D-53058, 16 pp., http://smap.jpl.nasa.gov/ files/smap2/044_soil_attrib.pdf.

—, D. Entekhabi, R. S. Dunbar, E. G. Njoku, and S. H. Yueh, 2016: Uncertainty estimates in the SMAP combined activepassive downscaled brightness temperature. IEEE Trans. Geosci. Remote Sens., 54, 640-650, https://doi.org/10.1109/ TGRS.2015.2450694.

De Lannoy, G. J., and R. H. Reichle, 2016a: Assimilation of SMOS brightness temperatures or soil moisture retrievals into a land surface model. Hydrol. Earth Syst. Sci., 20, 4895-4911, https:// doi.org/10.5194/hess-20-4895-2016.

$\ldots$ _ and _ 2 2016b: Global assimilation of multiangle and multipolarization SMOS brightness temperature observations into the GEOS-5 catchment land surface model for soil moisture estimation. J. Hydrometeor., 17, 669-691, https:// doi.org/10.1175/JHM-D-15-0037.1.

,,-- P. R. Houser, V. Pauwels, and N. E. Verhoest, 2007: Correcting for forecast bias in soil moisture assimilation with the ensemble Kalman filter. Water Resour. Res., 43, W09410, https://doi.org/10.1029/2006WR005449.

Dirmeyer, P. A., F. J. Zeng, A. Ducharne, J. C. Morrill, and R. D. Koster, 2000: The sensitivity of surface fluxes to soil water content in three land surface schemes. J. Hydrometeor., 1, 121-134, https://doi.org/10.1175/1525-7541(2000)001<0121:TSOSFT $>$ 2.0.CO;2.

Dobson, M. C., F. T. Ulaby, M. T. Hallikainen, and M. A. El-Rayes, 1985: Microwave dielectric behavior of wet soil-part ii: Dielectric mixing models. IEEE Trans. Geosci. Remote Sens., GE-23, 35-46, https://doi.org/10.1109/TGRS.1985.289498.

Dong, J., S. C. Steele-Dunne, J. Judge, and N. van de Giesen, 2015: A particle batch smoother for soil moisture estimation using soil temperature observations. Adv. Water Resour., 83, 111122, https://doi.org/10.1016/j.advwatres.2015.05.017.

$\longrightarrow,-$, T. E. Ochsner, and N. van de Giesen, 2016a: Estimating soil moisture and soil thermal and hydraulic properties by assimilating soil temperatures using a particle batch smoother. Adv. Water Resour., 91, 104-116, https://doi.org/10.1016/ j.advwatres.2016.03.008.

—_ and Coauthors, 2016b: Mapping high-resolution soil moisture and properties using distributed temperature sensing data and an adaptive particle batch smoother. Water Resour. Res., 52 , 7690-7710, https://doi.org/10.1002/2016WR019031.

Draper, C., R. Reichle, G. De Lannoy, and B. Scarino, 2015: A dynamic approach to addressing observation-minus-forecast bias in a land surface skin temperature data assimilation system. J. Hydrometeor., 16, 449-464, https://doi.org/10.1175/ JHM-D-14-0087.1.

Dunne, S., and D. Entekhabi, 2006: Land surface state and flux estimation using the ensemble Kalman smoother during the Southern Great Plains 1997 field experiment. Water Resour. Res., 42, W01407, https://doi.org/10.1029/2005WR004334.

Entekhabi, D., and Coauthors, 2014: SMAP Handbook Soil Moisture Active Passive: Mapping soil moisture and freeze/thaw from space. JPL CL14-2285, JPL Publ. 400-1567, Jet Propulsion Laboratory, 180 pp., https://smap.jpl.nasa.gov/system/internal_ resources/details/original/178_SMAP_Handbook_FINAL_1_ JULY_2014_Web.pdf.

Farhadi, L., D. Entekhabi, G. Salvucci, and J. Sun, 2014: Estimation of land surface water and energy balance parameters using conditional sampling of surface states. Water Resour. Res., 50, 1805-1822, https://doi.org/10.1002/ 2013WR014049.

$\ldots, \ldots$, and _ 2016: Mapping land water and energy balance relations through conditional sampling of remote sensing estimates of atmospheric forcing and surface states. Water Resour. Res., 52, 2737-2752, https://doi.org/10.1002/2015WR017680.

Gentine, P., D. Entekhabi, A. Chehbouni, G. Boulet, and B. Duchemin, 2007: Analysis of evaporative fraction diurnal behaviour. Agric. For. Meteor., 143, 13-29, https://doi.org/10.1016/ j.agrformet.2006.11.002.

Gupta, H. V., H. Kling, K. K. Yilmaz, and G. F. Martinez, 2009: Decomposition of the mean squared error and NSE performance criteria: Implications for improving hydrological modelling. J. Hydrol., 377, 80-91, https://doi.org/10.1016/j.jhydrol.2009.08.003.

Holmes, T. R., and Coauthors, 2006: A new parameterization of the effective temperature for L band radiometry. Geophys. Res. Lett., 33, L07405, https://doi.org/10.1029/2006GL025724.

— C. R. Hain, W. T. Crow, M. C. Anderson, and W. P. Kustas, 2018: Microwave implementation of two-source energy balance approach for estimating evapotranspiration. Hydrol. Earth Syst. Sci., 22, 1351-1369, https://doi.org/10.5194/hess-22-1351-2018.

Hou, A. Y., and Coauthors, 2014: The Global Precipitation Measurement mission. Bull. Amer. Meteor. Soc., 95, 701-722, https://doi.org/10.1175/BAMS-D-13-00164.1.

Houborg, R., M. F. McCabe, and F. Gao, 2016: A spatio-temporal enhancement method for medium resolution LAI (STEM-LAI). Int. J. Appl. Earth Obs. Geoinf., 47, 15-29, https://doi.org/ 10.1016/j.jag.2015.11.013.

Huete, A., C. Justice, and W. Van Leeuwen, 1999: Modis vegetation index (MOD13). Algorithm Theoretical Basis Doc., version 3, 129 pp., https://modis.gsfc.nasa.gov/data/atbd/atbd_mod13.pdf.

Huffman, G. J., D. T. Bolvin, and E. J. Nelkin, 2015: Integrated Multi-satellitE Retrievals for GPM (IMERG) technical documentation. NASA/GSFC Code 612 Tech. Doc., 48 pp., http:// pmm.nasa.gov/sites/default/files/document_files/IMERG_doc.pdf.

Jackson, T. J., 1993: III. Measuring surface soil moisture using passive microwave remote sensing. Hydrol. Processes, 7, 139152, https://doi.org/10.1002/hyp.3360070205.

Jiang, L., and S. Islam, 2001: Estimation of surface evaporation map over Southern Great Plains using remote sensing data. Water Resour. Res., 37, 329-340, https://doi.org/10.1029/ 2000WR900255.

Kandasamy, S., F. Baret, A. Verger, P. Neveux, and M. Weiss, 2013: A comparison of methods for smoothing and gap filling time series of remote sensing observations-application to MODIS LAI products. Biogeosciences, 10, 4055-4071, https:// doi.org/10.5194/bg-10-4055-2013. 
Klein, L., and C. Swift, 1977: An improved model for the dielectric constant of sea water at microwave frequencies. IEEE J. Oceanic Eng., 2, 104-111, https://doi.org/10.1109/JOE.1977.1145319.

Knyazikhin, Y., and Coauthors, 1999: MODIS leaf area index (LAI) and fraction of photosynthetically active radiation absorbed by vegetation (FPAR) product (MOD15). Algorithm Theoretical Basis Doc., 130 pp., https://modis.gsfc.nasa.gov/ data/atbd/atbd_mod15.pdf.

Kornelsen, K. C., and P. Coulibaly, 2015: Reducing multiplicative bias of satellite soil moisture retrievals. Remote Sens. Environ., 165, 109-122, https://doi.org/10.1016/j.rse.2015.04.031.

—, M. H. Cosh, and P. Coulibaly, 2015: Potential of bias correction for downscaling passive microwave and soil moisture data. J. Geophys. Res. Atmos., 120, 6460-6479, https://doi.org/ 10.1002/2015JD023550.

Kumar, S. V., R. H. Reichle, K. W. Harrison, C. D. Peters-Lidard, S. Yatheendradas, and J. A. Santanello, 2012: A comparison of methods for a priori bias correction in soil moisture data assimilation. Water Resour. Res., 48, W03515, https://doi.org/ 10.1029/2010WR010261.

Kustas, W., K. Humes, J. Norman, and M. Moran, 1996: Single-and dual-source modeling of surface energy fluxes with radiometric surface temperature. J. Appl. Meteor., 35, 110-121, https://doi.org/10.1175/1520-0450(1996)035<0110:SADSMO> 2.0.CO;2.

Lievens, H., and Coauthors, 2016: Assimilation of SMOS soil moisture and brightness temperature products into a land surface model. Remote Sens. Environ., 180, 292-304, https:// doi.org/10.1016/j.rse.2015.10.033.

, B. Martens, N. Verhoest, S. Hahn, R. Reichle, and D. Miralles, 2017a: Assimilation of global radar backscatter and radiometer brightness temperature observations to improve soil moisture and land evaporation estimates. Remote Sens. Environ., 189, 194-210, https://doi.org/10.1016/j.rse.2016.11.022.

_ similation to improve soil moisture estimates. Geophys. Res. Lett., 44, 6145-6153, https://doi.org/10.1002/2017GL073904.

Lu, S., Z. Ju, T. Ren, and R. Horton, 2009: A general approach to estimate soil water content from thermal inertia. Agric. For. Meteor., 149, 1693-1698, https://doi.org/10.1016/j.agrformet.2009.05.011.

Lu, Y., J. Dong, S. C. Steele-Dunne, and N. van de Giesen, 2016: Estimating surface turbulent heat fluxes from land surface temperature and soil moisture observations using the particle batch smoother. Water Resour. Res., 52, 9086-9108, https:// doi.org/10.1002/2016WR018943.

_ S. C. Steele-Dunne, L. Farhadi, and N. van de Giesen, 2017: Mapping surface heat fluxes by assimilating SMAP soil moisture and GOES land surface temperature data. Water Resour. Res., 53, 10 858-10 877, https://doi.org/10.1002/2017WR021415.

_ J. Dong, and S. C. Steele-Dunne, 2019: Impact of soil moisture data resolution on soil moisture and surface heat flux estimates through data assimilation-A case study in the Southern Great Plains. J. Hydrometeor., 20, 715-730, https://doi.org/10.1175/ JHM-D-18-0234.1.

Ma, N., and J. Szilagyi, 2019: The complementary relationship (CR) of evaporation: A calibration-free diagnostic and benchmarking tool for large-scale terrestrial evapotranspiration modeling. Water Resour. Res., 55, 7246-7274, https://doi.org/ 10.1029/2019WR024867.

Margulis, S. A., M. Girotto, G. Cortés, and M. Durand, 2015: A particle batch smoother approach to snow water equivalent estimation. J. Hydrometeor., 16, 1752-1772, https://doi.org/ 10.1175/JHM-D-14-0177.1.
McCabe, M. F., and E. F. Wood, 2006: Scale influences on the remote estimation of evapotranspiration using multiple satellite sensors. Remote Sens. Environ., 105, 271-285, https://doi.org/ 10.1016/j.rse.2006.07.006.

Minacapilli, M., S. Consoli, D. Vanella, G. Ciraolo, and A. Motisi, 2016: A time domain triangle method approach to estimate actual evapotranspiration: Application in a Mediterranean region using MODIS and MSG-SEVIRI products. Remote Sens. Environ., 174, 10-23, https://doi.org/ 10.1016/j.rse.2015.12.018.

Mironov, V. L., L. G. Kosolapova, and S. V. Fomin, 2009: Physically and mineralogically based spectroscopic dielectric model for moist soils. IEEE Trans. Geosci. Remote Sens., 47, 2059-2070, https://doi.org/10.1109/TGRS.2008.2011631.

Moradkhani, H., K.-L. Hsu, H. Gupta, and S. Sorooshian, 2005: Uncertainty assessment of hydrologic model states and parameters: Sequential data assimilation using the particle filter. Water Resour. Res., 41, W05012, https://doi.org/ 10.1029/2004WR003604.

_ C. M. DeChant, and S. Sorooshian, 2012: Evolution of ensemble data assimilation for uncertainty quantification using the particle filter-Markov chain Monte Carlo method. Water Resour. Res., 48, W12520, https://doi.org/10.1029/2012WR012144.

Njoku, E. G., and D. Entekhabi, 1996: Passive microwave remote sensing of soil moisture. J. Hydrol., 184, 101-129, https:// doi.org/10.1016/0022-1694(95)02970-2.

Oleson, K. W., and Coauthors, 2010: Technical description of version 4.0 of the Community Land Model (CLM). NCAR Tech. Note NCAR/TN-478+STR, 257 pp., https://doi.org/ 10.5065/D6FB50WZ.

O’Neill, P., E. Njoku, T. Jackson, S. Chan, and R. Bindlish, 2015: SMAP algorithm theoretical basis document: Level $2 \& 3$ soil moisture (passive) data products. JPL D-66480, 80 pp., http:// smap.jpl.nasa.gov/system/internal_resources/details/original/ 316_L2_SM_P_ATBD_v7_Sep2015.pdf.

Pan, M., X. Cai, N. W. Chaney, D. Entekhabi, and E. F. Wood, 2016: An initial assessment of SMAP soil moisture retrievals using high-resolution model simulations and in situ observations. Geophys. Res. Lett., 43, 9662-9668, https://doi.org/ 10.1002/2016GL069964.

Pinker, R. T., D. Sun, M.-P. Hung, C. Li, and J. B. Basara, 2009: Evaluation of satellite estimates of land surface temperature from GOES over the United States. J. Appl. Meteor. Climatol., 48, 167-180, https://doi.org/10.1175/2008JAMC1781.1.

Reichle, R. H., and R. D. Koster, 2004: Bias reduction in short records of satellite soil moisture. Geophys. Res. Lett., 31, L19501, https://doi.org/10.1029/2004GL020938.

—, W. Crow, R. Koster, J. Kimball, and G. De Lannoy, 2012: SMAP level 4 surface and root zone soil moisture (L4_SM) data product. Algorithm Theoretical Basis Doc., 77 pp.

- R. D. Koster, J. Dong, and A. A. Berg, 2004: Global soil moisture from satellite observations, land surface models, and ground data: Implications for data assimilation. J. Hydrometeor., 5, 430-442, https://doi.org/10.1175/1525-7541(2004)005<0430: GSMFSO $>2.0 . \mathrm{CO} ; 2$.

_- S. V. Kumar, S. P. Mahanama, R. D. Koster, and Q. Liu, 2010: Assimilation of satellite-derived skin temperature observations into land surface models. J. Hydrometeor., 11, 1103-1122, https://doi.org/10.1175/2010JHM1262.1.

_, and Coauthors, 2017a: Assessment of the SMAP level-4 surface and root-zone soil moisture product using in situ measurements. J. Hydrometeor., 18, 2621-2645, https://doi.org/ 10.1175/JHM-D-17-0063.1. 
, and Coauthors, 2017b: Global assessment of the SMAP level-4 surface and root-zone soil moisture product using assimilation diagnostics. J. Hydrometeor., 18, 3217-3237, https://doi.org/ 10.1175/JHM-D-17-0130.1.

Sahoo, A. K., G. J. De Lannoy, R. H. Reichle, and P. R. Houser, 2013: Assimilation and downscaling of satellite observed soil moisture over the Little River experimental watershed in Georgia, USA. Adv. Water Resour., 52, 19-33, https://doi.org/ 10.1016/j.advwatres.2012.08.007.

Santanello, J. A., Jr., C. D. Peters-Lidard, and S. V. Kumar, 2011: Diagnosing the sensitivity of local land-atmosphere coupling via the soil moisture-boundary layer interaction. J. Hydrometeor., 12, 766-786, https://doi.org/10.1175/JHM-D-10-05014.1.

Schaap, M. G., F. J. Leij, and M. T. Van Genuchten, 2001: ROSETTA: A computer program for estimating soil hydraulic parameters with hierarchical pedotransfer functions. J. Hydrol., 251, 163-176, https://doi.org/10.1016/S0022-1694(01)00466-8.

Schaefer, G. L., M. H. Cosh, and T. J. Jackson, 2007: The USDA natural resources conservation service Soil Climate Analysis Network (SCAN). J. Atmos. Oceanic Technol., 24, 2073-2077, https://doi.org/10.1175/2007JTECHA930.1.

Sellers, P., Y. Mintz, Y. Sud, and A. Dalcher, 1986: A Simple Biosphere Model $(\mathrm{SiB})$ for use within general circulation models. J. Atmos. Sci., 43, 505-531, https://doi.org/10.1175/ 1520-0469(1986)043<0505:ASBMFU>2.0.CO;2.

Semmens, K. A., and Coauthors, 2016: Monitoring daily evapotranspiration over two California vineyards using Landsat 8 in a multi-sensor data fusion approach. Remote Sens. Environ., 185, 155-170, https://doi.org/10.1016/j.rse.2015.10.025.

Shellito, P. J., and Coauthors, 2016: SMAP soil moisture drying more rapid than observed in situ following rainfall events. Geophys. Res. Lett., 43, 8068-8075, https://doi.org/10.1002/2016GL069946.

Sini, F., G. Boni, F. Caparrini, and D. Entekhabi, 2008: Estimation of large-scale evaporation fields based on assimilation of remotely sensed land temperature. Water Resour. Res., 44, W06410, https://doi.org/10.1029/2006WR005574.

$\mathrm{Su}, \mathrm{C} .-\mathrm{H}$. , and D. Ryu, 2015: Multi-scale analysis of bias correction of soil moisture. Hydrol. Earth Syst. Sci., 19, 17-31, https:// doi.org/10.5194/hess-19-17-2015.

Su, Z., 2002: The Surface Energy Balance System (SEBS) for estimation of turbulent heat fluxes. Hydrol. Earth Syst. Sci., 6, 85-100, https://doi.org/10.5194/hess-6-85-2002.

Sun, D., and R. T. Pinker, 2003: Estimation of land surface temperature from a Geostationary Operational Environmental Satellite (GOES-8). J. Geophys. Res., 108, 4326, https://doi.org/ 10.1029/2002JD002422.

Thyng, K. M., C. A. Greene, R. D. Hetland, H. M. Zimmerle, and S. F. DiMarco, 2016: True colors of oceanography: Guidelines for effective and accurate colormap selection. Oceanography, 29, 9-13, https://doi.org/10.5670/oceanog.2016.66.

Tian, X., Z. Xie, A. Dai, C. Shi, B. Jia, F. Chen, and K. Yang, 2009: A dual-pass variational data assimilation framework for estimating soil moisture profiles from AMSR-E microwave brightness temperature. J. Geophys. Res., 114, D16102, https:// doi.org/10.1029/2008JD011600.

Wang, J. R., and T. J. Schmugge, 1980: An empirical model for the complex dielectric permittivity of soils as a function of water content. IEEE Trans. Geosci. Remote Sens., GE-18, 288-295, https://doi.org/10.1109/TGRS.1980.350304.

Wigneron, J.-P., L. Laguerre, and Y. H. Kerr, 2001: A simple parameterization of the L-band microwave emission from rough agricultural soils. IEEE Trans. Geosci. Remote Sens., 39, 16971707, https://doi.org/10.1109/36.942548.

, A. Chanzy, P. De Rosnay, C. Rudiger, and J.-C. Calvet, 2008: Estimating the effective soil temperature at L-band as a function of soil properties. IEEE Trans. Geosci. Remote Sens., 46, 797807, https://doi.org/10.1109/TGRS.2007.914806.

Xia, Y., and Coauthors, 2012: Continental-scale water and energy flux analysis and validation for the North American Land Data Assimilation System project phase 2 (NLDAS-2): 1. Intercomparison and application of model products. J. Geophys. Res., 117, D03109, https://doi.org/10.1029/2011JD016048.

Xu, T., S. Bateni, S. Liang, D. Entekhabi, and K. Mao, 2014: Estimation of surface turbulent heat fluxes via variational assimilation of sequences of land surface temperatures from Geostationary Operational Environmental Satellites. J. Geophys. Res. Atmos., 119, $10780-107$ 98, https://doi.org/10.1002/ 2014JD021814.

- - C. Neale, T. Auligne, and S. Liu, 2018: Estimation of turbulent heat fluxes by assimilation of land surface temperature observations from GOES satellites into an ensemble Kalman smoother framework. J. Geophys. Res. Atmos., 123, 2409-2423, https://doi.org/10.1002/2017JD027732.

— X. Xe, S. M. Bateni, T. Auligne, S. Liu, Z. Xu, J. Zhou, and K. Mao, 2019: Mapping regional turbulent heat fluxes via variational assimilation of land surface temperature data from polar orbiting satellites. Remote Sens. Environ., 221, 444-461, https://doi.org/10.1016/j.rse.2018.11.023.

Yan, H., C. M. DeChant, and H. Moradkhani, 2015: Improving soil moisture profile prediction with the particle filter-Markov chain Monte Carlo method. IEEE Trans. Geosci. Remote Sens., 53, 6134-6147, https://doi.org/10.1109/TGRS.2015.2432067.

Yang, K., and Coauthors, 2016: Land surface model calibration through microwave data assimilation for improving soil moisture simulations. J. Hydrol., 533, 266-276, https://doi.org/ 10.1016/j.jhydrol.2015.12.018.

Yilmaz, M. T., and W. T. Crow, 2013: The optimality of potential rescaling approaches in land data assimilation. J. Hydrometeor., 14, 650-660, https://doi.org/10.1175/JHM-D-12-052.1.

Zhao, L., Z.-L. Yang, and T. J. Hoar, 2016: Global soil moisture estimation by assimilating AMSR-E brightness temperatures in a coupled CLM4-RTM-DART system. J. Hydrometeor., 17, 2431-2454, https://doi.org/10.1175/JHM-D-15-0218.1.

Zheng, D., R. van der Velde, Z. Su, X. Wang, J. Wen, M. J. Booij, A. Y. Hoekstra, and Y. Chen, 2015: Augmentations to the Noah model physics for application to the Yellow River source area. Part II: Turbulent heat fluxes and soil heat transport. J. Hydrometeor., 16, 2677-2694, https://doi.org/ 10.1175/JHM-D-14-0199.1.

Zhu, W., S. Jia, and A. Lv, 2017: A universal Ts-VI triangle method for the continuous retrieval of evaporative fraction from MODIS products. J. Geophys. Res. Atmos., 122, 10 206-10 227, https://doi.org/10.1002/2017JD026964. 